\title{
Leguminosae na Floresta Ombrófila Densa do Núcleo Santa Virgínia, Parque Estadual da Serra do Mar, São Paulo, Brasil
}

Leguminosae in Ombrophilous Dense Forest of Santa Virgínia Nucleus, Serra do Mar State Park, São Paulo, Brazil

\author{
Edson Dias da Silva ${ }^{1,2}$ \& Ana Maria Goulart de Azevedo Tozzi ${ }^{1}$
}

\begin{abstract}
Resumo
O presente estudo traz o levantamento florístico das espécies de Leguminosae que ocorrem em uma área de Floresta Ombrófila Densa do litoral norte do estado de São Paulo, em altitudes que variam de 16 a 1168 metros de altitude. O levantamento florístico envolveu coletas de plantas arbóreas, arbustivas, herbáceas e lianas. A família Leguminosae está representada na Floresta Ombrófila Densa do Núcleo Santa Virgínia por 82 espécies. Vinte e sete espécies encontradas são endêmicas da Floresta Atlântica. Além de uma lista de gêneros e espécies com suas respectivas chaves de identificação também são apresentadas ilustrações e informações sobre distribuição geográfica.
\end{abstract}

Palavras-chave: Fabaceae, Floresta Atlântica, leguminosas, levantamento florístico.

\begin{abstract}
This study present the floristic survey of the Leguminosae species occurring in an area of Ombrophilous Dense Forest from the north coast of the state of São Paulo, in altitudes that varying from 16 to 1,169 meters of altitude. The floristic survey involved the collecting of herbs, shrubs, trees and lianas. The Leguminosae family is represented in the Ombrophilous Dense Forest of Santa Virgínia Nucleus by 82 species. Twenty seven species are endemic to the Atlantic Forest. Besides a genera and species list with their corresponding identification keys, illustrations, information on geographical distribution are also presented.
\end{abstract}

Key words: Fabaceae, Atlantic Forest, leguminosas, floristic survey.

\section{Introdução}

Considerada a quinta área mais ameaçada $\mathrm{e}$ rica em espécies no mundo, a Floresta Atlântica está atualmente reduzida a pequenos fragmentos florestais, que representam apenas $7,6 \%$ da formação original. Infelizmente, a exploração de vários tipos de madeira e a substituição da mata nativa por plantações de cana-de-açúcar, café, cacau ou pasto tem reduzido a floresta a pequenos remanescentes (Mori et al. 1981; LeitãoFilho 1994). A maior parte dos remanescentes contínuos de Floresta Atlântica está localizada principalmente na costa do estado de São Paulo e do Paraná, no sudeste do Brasil, devido principalmente ao relevo irregular da Serra do Mar e Serra de Paranapiacaba (Leitão-Filho 1994). Em
São Paulo, onde há apenas 5\% de florestas nativas com pouca ação antrópica, destaca-se as regiões serranas, principalmente a fachada da Serra do Mar (Kronka et al. 2003).

Leguminosae, constituída por aproximadamente 727 gêneros e 19.327 espécies (Lewis et al. 2005), é a segunda maior família de eudicotiledôneas em número de espécies e a segunda mais importante economicamente no mundo ficando atrás apenas de Poaceae. É composta por três subfamílias: Caesalpinioideae que é formada por quatro tribos, 171 gêneros e 2.250 espécies; Mimosoideae, constituída de quatro tribos, 78 gêneros e 3.270 espécies e Papilionoideae (= Faboideae), que é a maior das três subfamílias, compreende 28 tribos de 478

\footnotetext{
${ }^{1}$ Universidade Estadual de Campinas, Inst. Biologia, Depto. Biologia Vegetal, C.P. 6109, 13083-970, Campinas, SP, Brasil.

${ }^{2}$ Autor para correspondência: edsonxv@gmail.com
} 
gêneros e 13.800 espécies (Lewis et al. 2005). Para o Brasil foram catalogados cerca de 212 gêneros e 2.720 espécies de Leguminosae (Lima et al. 2012), cuja ocorrência é muito significativa na maioria dos tipos vegetacionais, em especial da Floresta Atlântica, onde a família possui elevada representatividade entre os elementos do estrato arbóreo (Lima 2000). Estimativas recentes de Lima et al. (2009) listam 945 espécies de Leguminosae para a Floresta Atlântica, sendo 394 exclusivas.

Levantamentos florísticos e estudos fitossociológicos realizados em várias regiões da Floresta Atlântica já atestaram a importância da família Leguminosae na composição e estrutura desse bioma. Em estudos realizados no estado de São Paulo, Rio de Janeiro e Paraná (Tab. 1) Leguminosae está entre as três famílias mais bem representadas em número de espécies. Para a Floresta Atlântica do estado de São Paulo, onde é expressiva a representatividade da família, no entanto, são escassos os levantamentos florísticos realizados em diferentes áreas remanescentes, especialmente levantamentos das subfamílias Caesalpinioideae e Mimosoideae. O objetivo deste trabalho foi apresentar o levantamento florístico das espécies de Leguminosae que ocorrem em uma área de Floresta Ombrófila Densa do litoral norte do estado de São Paulo.

\section{Material e Métodos}

A área de estudo está localizada na região nordeste do estado de São Paulo, no Núcleo Santa Virgínia, Parque Estadual Serra do Mar (Fig. 1). A área do Núcleo abrange atualmente os municípios de São Luiz do Paraitinga (70\%), Cunha (20\%) e Ubatuba (10\%). Os locais de coleta estão situados próximos à Sede do Núcleo Santa

Tabela 1 - Levantamentos florísticos e fitossociológicos realizados na Floresta Ombrófila Densa nos estados de São Paulo, Rio de Janeiro e Paraná ressaltando a presença da família Leguminosae entre as famílias com maior número de espécies. * indica onde as três subfamílias de Leguminosae foram consideradas como famílias distintas.

Table 1 - Floristic and phytosociological surveys carried out in the Ombrophilous Dense Forest in São Paulo, Rio de Janeiro and Paraná highlighting the presence of the Leguminosae family among families with the greatest number of species. * indicates when the three subfamilies of Leguminosae were regarded as distinct families.

\begin{tabular}{|c|c|c|c|c|c|}
\hline \multirow[b]{2}{*}{ Autores } & \multicolumn{3}{|c|}{ Estudo } & \multicolumn{2}{|c|}{ Resultado de interesse } \\
\hline & natureza & local & altitude & $\begin{array}{c}\mathrm{n}^{\circ} \text { spp. de } \\
\text { Leguminosae }\end{array}$ & $\begin{array}{c}\text { famílias com maior } \\
n^{\circ} \text { espécies }\end{array}$ \\
\hline $\begin{array}{l}\text { Silva \& Leitão } \\
\text { Filho (1982) }\end{array}$ & $\begin{array}{l}\text { Florística e } \\
\text { fitossociologia } \\
\text { (árvores) }\end{array}$ & $\begin{array}{l}\text { mata atlântica de encosta, } \\
\text { Ubatuba, SP. }\end{array}$ & $\begin{array}{l}20-90 \mathrm{~m} \mathrm{e} \\
160-190 \mathrm{~m}\end{array}$ & 10 & $\begin{array}{l}\text { Myrtaceae (16); } \\
\text { Lauraceae (12); } \\
\text { Leguminosae (10) }\end{array}$ \\
\hline $\begin{array}{l}\text { Barros et al. } \\
\text { (1991) }\end{array}$ & $\begin{array}{l}\text { Florística } \\
\text { (todos os hábitos) }\end{array}$ & Ilha do Cardoso, Cananéia, SP. & 0 a $800 \mathrm{~m}$ & 63 & $\begin{array}{l}\text { Orchidaceae (118); } \\
\text { Myrtaceae (70); } \\
\text { Leguminosae (63) }\end{array}$ \\
\hline Marques (1997) & $\begin{array}{l}\text { Florística e } \\
\text { fitossociologia (todos } \\
\text { os hábitos) }\end{array}$ & $\begin{array}{l}\text { Área de Proteção Ambiental de } \\
\text { Cairuçu, Parati, RJ. }\end{array}$ & $\begin{array}{l}\text { nível do mar a } \\
1320 \mathrm{~m}\end{array}$ & 60 & $\begin{array}{l}\text { Myrtaceae (71); } \\
\text { Leguminosae (63); } \\
\text { Rubiaceae (52) }\end{array}$ \\
\hline Silva (1998) & $\begin{array}{l}\text { Florística e } \\
\text { fitossociologia } \\
\text { (árvores e arbustos) }\end{array}$ & $\begin{array}{l}\text { planície costeira da Ilha do } \\
\text { Mel, Paranaguá, PR. }\end{array}$ & & 33 & $\begin{array}{c}\text { Leguminosae (33)*; } \\
\text { Myrtaceae (24), } \\
\text { Asteraceae (19) }\end{array}$ \\
\hline Lacerda (2001) & $\begin{array}{l}\text { Florística e } \\
\text { fitossociologia } \\
\text { (árvores) }\end{array}$ & Picinguaba, SP. & $\begin{array}{l}2,100,300 \\
600 \text { e } 1000 \mathrm{~m}\end{array}$ & 29 & $\begin{array}{l}\text { Myrtaceae (60); } \\
\text { Leguminosae (29); } \\
\text { Rubiaceae }(26)^{*}\end{array}$ \\
\hline $\begin{array}{l}\text { Mamede et al. } \\
\text { (2004) }\end{array}$ & Florística (árvores) & Serra da Juréia, Iguape, SP. & 5 a $300 \mathrm{~m}$ & 28 & $\begin{array}{l}\text { Myrtaceae (52); } \\
\text { Leguminosae (28); } \\
\text { Rubiaceae (25) }\end{array}$ \\
\hline Schmidlin (2005) & Florística (árvores) & $\begin{array}{l}\text { Ilha Superagui, Guaraqueçaba, } \\
\text { PR. }\end{array}$ & & 19 & $\begin{array}{c}\text { Myrtaceae (9); } \\
\text { Lauraceae (6); } \\
\text { Leguminosae (19)* }\end{array}$ \\
\hline
\end{tabular}




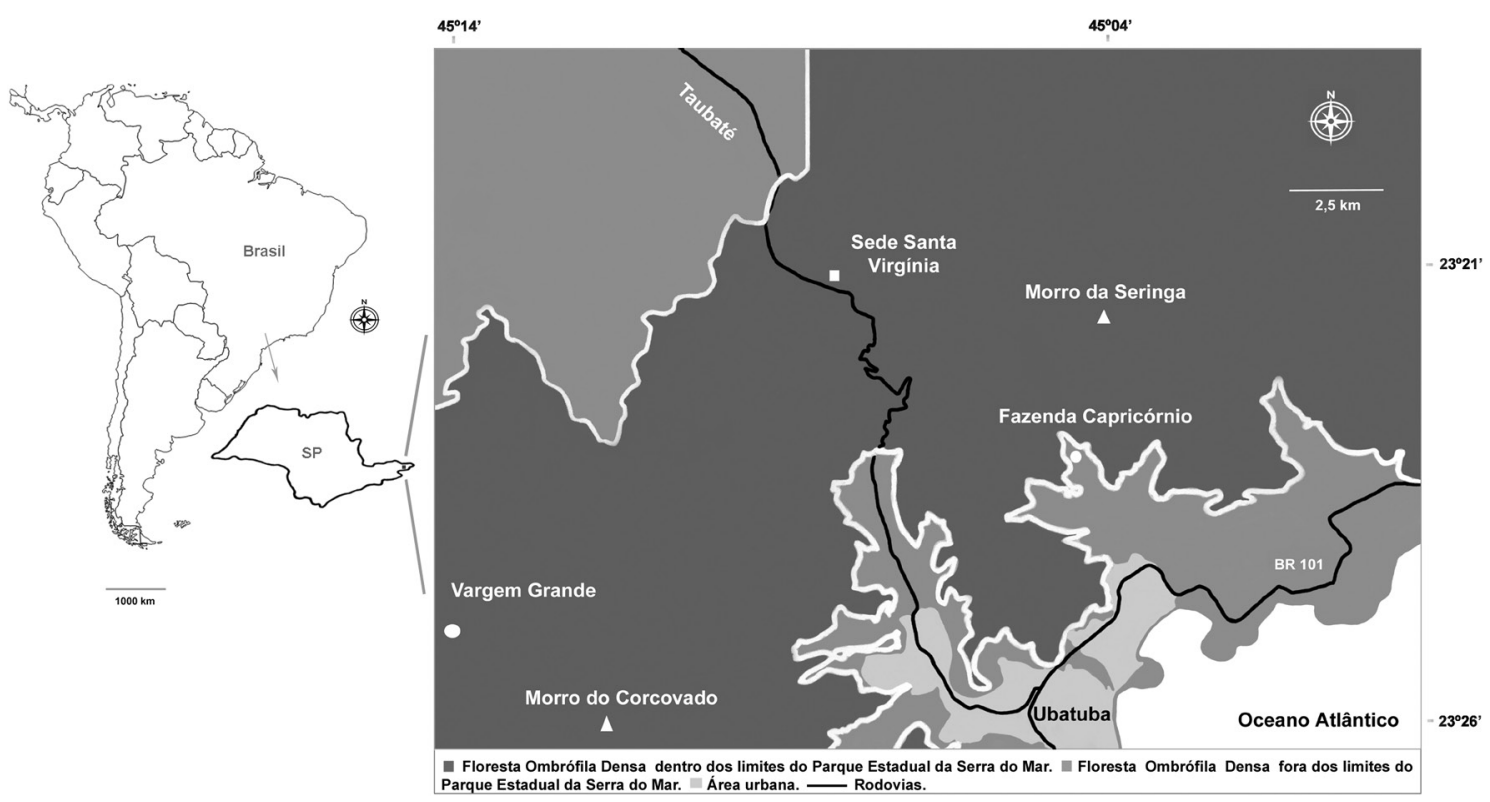

Figura 1 - Mapa da área de estudo no Núcleo Santa Virgínia, Parque Estadual da Serra do Mar.

Figure 1 - Map of study area in Santa Virgínia Nucleus, Serra do Mar State Park.

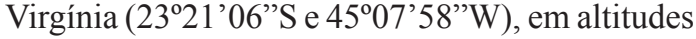
que variam de 850 a $1100 \mathrm{~m}$; próximas a Base de Vargem Grande (23⒉ $6^{\prime} 17^{\prime \prime} \mathrm{S}$ e $\left.45^{\circ} 14^{\prime} 41^{\prime \prime} \mathrm{W}\right)$ a $819 \mathrm{~m}$ altitude até a vegetação do topo do Morro

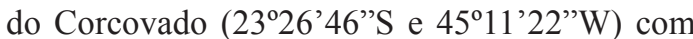
aproximadamente $1.168 \mathrm{~m}$ altitude e próximos a cidade de Ubatuba em altitudes que variam de 16 m, na Fazenda Capricórnio $\left(23^{\circ} 23^{\prime} 55^{\prime}\right.$ 'S e $45^{\circ} 04^{\prime} 03^{\prime \prime} \mathrm{W}$ ), até a vegetação do topo do Morro da Seringa $\left(23^{\circ} 21^{\prime} 14^{\prime \prime}\right.$ S e $\left.45^{\circ} 04^{\prime} 56^{\prime} \mathrm{W}\right)$ a 1.090 $\mathrm{m}$ altitude. Também foram realizadas coletas ao longo da Rodovia Oswaldo Cruz, que liga cidade de Ubatuba à Sede do Núcleo Santa Virgínia, no alto da Serra do Mar.

O levantamento florístico envolveu coletas de plantas herbáceas, subarbustivas, arbustivas, arbóreas e lianas percorrendo trilhas nas diferentes formações vegetais. A classificação quanto ao hábito seguiu o proposto por Whittaker (1975). As viagens à área de estudo foram realizadas mensalmente entre 2006 e 2009 percorrendo trilhas nas diferentes fitofisionomias: Floresta Ombrófila Densa de Terras Baixas, Floresta Ombrófila Densa Submontana e Floresta Ombrófila Densa Montana de acordo com o sistema de classificação proposto por Veloso et al. (1991).

Todo o material coletado está incorporado ao acervo do Herbário UEC. A listagem final foi complementada com coletas dos seguintes herbários (acrônimos segundo Thiers, continuamente atualizado): ESA, HB, HRCB, MBM, NY, R, RB, SP, SPF e US. A lista com todo material examinado em visitas pessoais aos herbários citados está disponível para consulta on line no endereço eletrônico $<$ http://www.bibliotecadigital. unicamp.br/document $/$ ?code $=000625263 \&$ opt $=4$ > . Também foram consultadas as coletas de outros pesquisadores participantes do projeto temático Biota Gradiente, no qual este projeto estava inserido.

A terminologia utilizada nos frutos está baseada em Barroso et al. (1999). Após o nome do gênero acompanhado da obra principal, sempre que possível, é fornecida uma referência adicional, geralmente um trabalho de revisão taxonômica desse gênero. No presente trabalho, não foram adotadas categorias infraespecíficas principalmente devido ao fato de que em gêneros como Senna, Chamaecrista e Mimosa há um grande número de táxons infraespecíficos, os quais geralmente apresentam problemas de circunscrição. Assim, as identificações estão no nível de espécie. Os dados de distribuição geográfica são resultados da coleta de informações contidas em revisões e teses, material de herbário e sites que contenham informações de distribuição geográfica (Lima et al. 2012; Ilds 2012; Species Link 2012). 


\section{Resultados e Discussão}

Leguminosae Juss., Gen. Pl., 345. 1789

Bentham (1862), Barroso (1965), Cowan (1981), Elias (1981), Polhill (1981), Barroso et al. (1986), Barneby \& Heald (2002a e 2002b), Grimes (2002) e Lewis et al. (2005).

A maioria das espécies da família Leguminosae apresenta folhas compostas, alternas com pulvino desenvolvido e estípulas, o que facilita o seu reconhecimento no campo quando em estado vegetativo. Em geral, é possível separar os membros das três subfamílias, a partir da combinação de alguns caracteres. A maioria das espécies de Mimosoideae apresenta folhas bipinadas (Fig. 2a) com nectários no pecíolo, raque ou folíolo e flores actinomorfas, agregadas em
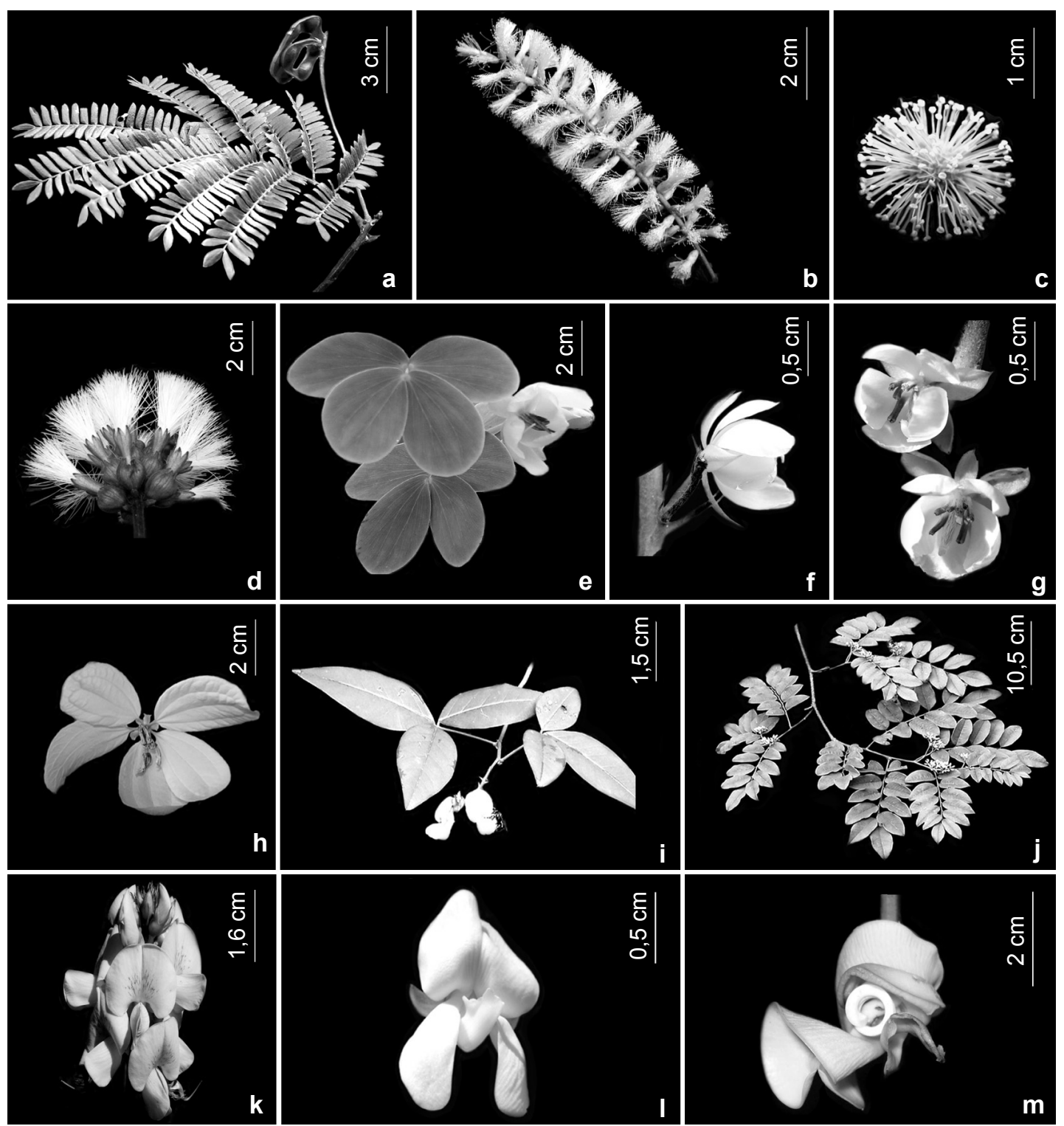

Figura 2 - a. Abarema langsdorffii (Silva 714); b. Senegalia lacerans (Silva 629); c. Mimosa scabrella (Silva 364); d. Inga hispida (Silva 1169); e. Chamaecrista desvauxii (Silva 1109); f. Chamaecrista glandulosa (Silva 1068); g. Chamaecrista nictitans (Silva 1078); h. Senna macranthera (Silva 709); i. Crotalaria vitellina (Silva 986); j. Dalbergia frutescens (Silva 1110); k. Crotalaria micans (Silva 610); 1. Dioclea rufescens (Silva 1117); m. Cochliasanthus caracalla (Silva 1144).

Figure2-a.Abarema langsdorffi (Silva 714); b. Senegalia lacerans (Silva 629); c. Mimosa scabrella(Silva364); d. Inga hispida(Silva 1169); e. Chamaecrista desvauxii(Silva 1109); f.Chamaecristaglandulosa(Silva 1068); g.Chamaecristanictitans (Silva 1078); h. Sennamacranthera (Silva 709); i.Crotalaria vitellina (Silva986);j.Dalbergia frutescens (Silva 1110);k. Crotalaria micans (Silva610); 1.Dioclearufescens (Silva 1117); m. Cochliasanthus caracalla (Silva 1144). 
inflorescências espiciformes (Fig. 2b), glomérulos (Fig. 2c) ou em racemos subglobosos (Fig. 2d). Grande parte das espécies de Caesalpinioideae possui folhas pinadas (Fig. 2e) e geralmente sem nectários, flores na maioria zigomorfas, às vezes com uma pétala superior sobreposta pelas demais (Fig. 2f-h). Espécies de Papilionoideae podem ser reconhecidas por apresentar folhas principalmente trifolioladas (Fig. 2i) ou pinadas (Fig. 2j), flores zigomorfas, com a pétala superior formando o vexilo ou estandarte (Fig. 2k-m).

$\mathrm{Na}$ área de estudo foram encontradas 82 espécies e 35 gêneros de Leguminosae. Existem representantes das quatro tribos de Caesalpinioideae, três tribos de Mimosoideae, a maioria composta de espécies de hábito arbóreo (Tab. 2) e sete tribos de Papilionoideae. Os gêneros mais representativos são: Inga (9 spp.), Machaerium (7 spp.), Mimosa (5 spp.) e Crotalaria (5 spp.). As tribos mais bem representadas são: Dalbergieae (5 gêneros, 15 spp.), Ingeae (3 gêneros, 13 spp.) e Mimoseae (4 gêneros, 11 spp.).

Das 82 espécies encontradas na área de estudo, 17 são pantropicais e amplamente distribuídas, 15 são exclusivamente sulamericanas e 37 são endêmicas do Brasil, sendo vinte e sete encontradas apenas na Floresta Atlântica.

Tabela 2 - Número de táxons de Leguminosae ocorrentes no Núcleo Santa Virgínia, Parque Estadual da Serra do Mar e seus respectivos hábitos.

Table 2 - Number of taxa of Leguminosae occurring in the Santa Virgínia Nucleus, Serra do Mar State Park and their habits.

\begin{tabular}{|c|c|c|c|c|c|c|}
\hline & \multicolumn{3}{|c|}{ táxons } & \multicolumn{3}{|c|}{ hábitos } \\
\hline & tribos & gêneros & espécies & subarbustivo-arbustivo & arbóreo & liana \\
\hline Caesalpinioideae & 4 & 9 & 16 & 5 & 9 & 2 \\
\hline Mimosoideae & 3 & 8 & 27 & 2 & 21 & 4 \\
\hline Papilionoideae & 7 & 18 & 39 & 13 & 15 & 11 \\
\hline total & 14 & 35 & 82 & 20 & 45 & 17 \\
\hline
\end{tabular}

\section{Subfamília Caesalpinioideae}

$\mathrm{Na}$ área de estudo foram encontradas 16 espécies pertencentes a nove gêneros e quatro tribos, sendo nove de hábito arbóreo, cinco subarbustivo-arbustivo e duas lianas. Seus gêneros podem ser reconhecidos a partir da chave apresentada a seguir, na qual estão ilustrados os principais caracteres diagnósticos (Fig. 3. a-g):

\section{Chave para os gêneros de Caesalpinioideae no Parque Estadual da Serra do Mar, São Paulo}

1. Folhas bipinadas.

2. Folíolos das pinas opostos; fruto obovado, valvas não torcidas na deiscência, semente única ..... Schizolobium

2'. Folíolos das pinas alternos; fruto oblongo, valvas torcidas na deiscência, mais de uma semente .... Poincianella

1'. Folhas pinadas, unifolioladas (ou aparentemente unifolioladas pelo concrescimento dos folíolos) ou bifolioladas.

3. Folhas unifolioladas ou bifolioladas.

4. Folhas unifolioladas, folíolos sem pontuações translúcidas; fruto legume ou legume samaróide.

5. Árvores, ramos sem gavinhas Bauhinia

5. Lianas, ramos com gavinhas Phanera

4'. Folhas bifolioladas, folíolos com pontuações translúcidas; legume nucóide Hymenaea

3'. Folhas pinadas.

6. Folíolos alternos, com pontuações translúcidas; flor apétala; legume com valvas côncavas Copaifera

6'. Folíolos opostos, sem pontuações translúcidas; flor com pétalas, legume com valvas retas ou enrolando-se na deiscência, folículo ou sâmara.

7. Fruto sâmara, semente única; filetes pilosos na base Tachigali 
7'. Fruto legume, folículo ou outro tipo de fruto indeiscente (não sâmara), mais de uma semente; filetes glabros na base.

8. Bractéolas ausentes; fruto indeiscente, deiscente através de uma única margem (folículo) ou, se deiscente por ambas as margens (legume), valvas não torcidas na deiscência Senna

8'. Bractéolas 2; legume com deiscência elástica, valvas torcidas na deiscência Chamaecrista

1. Bauhinia L., Sp. P1. 1: 374. 1753.

Referências: Vaz 1979, 1993; Fortunato 1986.

1.1 Bauhinia forficata Link, Enaum. Hort. Berol. Alt. 1: 404. 1821.

Material selecionado: BRASIL. SÃO PAULO: Núcleo Santa Virgínia, Parque Estadual da Serra do Mar, 17.XI.2007, fl., E.D. Silva 989 (UEC).
Distribuição geográfica: América do Central e do Sul. Brasil (Sul, Sudeste e Nordeste).

Domínio fitogeográfico brasileiro: Mata Atlântica.

2. Chamaecrista Moench, Methodus 272. 1794.

Referências: Irwin \& Barneby 1982b, Camargo \& Miotto 2004.

\section{Chave de identificação das espécies de Chamaecrista no Parque Estadual da Serra do Mar, São Paulo}

1. Folhas 2-4-folioladas, folíolos obovados.

2. Folhas 4-folioladas, pecíolo com nectário extrafloral presente C. desvauxii

2. Folhas 2-folioladas, pecíolo com nectário extrafloral ausente C. rotundifolia

1'. Folhas com mais de 4 folíolos, folíolos oblongos.

3. Nervura principal do folíolo fortemente excêntrica, pecíolo com nectário extrafloral séssil, planta frequentemente monopodial .... C. nictitans

3'. Nervura principal do folíolo central ou levemente deslocada para a margem, pecíolo com nectário extrafloral estipitado, planta simpodial C. glandulosa

2.1. Chamaecrista desvauxii (Collad.) Killip, Brittonia 3(2): 165. 1939.

Material selecionado: BRASIL. SÃO PAULO: Núcleo Santa Virgínia, Parque Estadual da Serra do Mar, 22.V.2008, fl. e fr., E.D. Silva 1109 (UEC).

Distribuição geográfica: América Central e do Sul. Brasil (todas as regiões).

Domínio fitogeográfico brasileiro: Amazônia, Caatinga, Cerrado, Mata Atlântica e Pantanal.

2.2 Chamaecrista glandulosa Greene, Pittonia 4: 28. 1899.

Material selecionado: BRASIL. SÃO PAULO: Núcleo Santa Virgínia, Parque Estadual da Serra do Mar, 28.I.2008, f1., E.D. Silva 1068 (UEC).

Distribuição geográfica: América Central e do Sul. Brasil (todas as regiões).

Domínio fitogeográfico brasileiro: Amazôniae MataAtlântica.

2.3 Chamaecrista nictitans (L.) Moench, Methodus (Moench) 272. 1794.
Material selecionado: BRASIL. SÃO PAULO: Núcleo Santa Virgínia, Parque Estadual da Serra do Mar, 28.I.2008, fl. e fr., E.D. Silva 1078 (UEC).

Distribuição geográfica: Pantropical. Brasil (todas as regiões).

Domínio fitogeográfico brasileiro: Amazônia, Caatinga, Cerrado e Mata Atlântica.

2.4 Chamaecrista rotundifolia (Pers.) Greene, Pittonia 4: 31. 1899.

Material selecionado: BRASIL. SÃO PAULO: Núcleo Santa Virgínia, Parque Estadual da Serra do Mar, 28.I.2008, f1., E.D. Silva 1072 (UEC).

Distribuição geográfica: América Central e do Sul com disjunção na África. Brasil (todas as regiões).

Domínio fitogeográfico brasileiro: Amazônia, Caatinga, Cerrado, Mata Atlântica, Pampa e Pantanal.

3. Copaifera L., Sp. Pl. 1: 557. 1762.

\section{Chave de identificação das espécies de Copaifera no Parque Estadual da Serra do Mar, São Paulo}

1. Folíolos falcado-lanceolados, 3,5-8,5 × 2-3,5 cm, pilosos em ambas as faces. C. langsdorffii

1. Folíolos trapeziformes, $1-2 \times 0,5-0,8 \mathrm{~cm}$, pilosos apenas ao longo da nervura central da face abaxial C. trapezifolia 

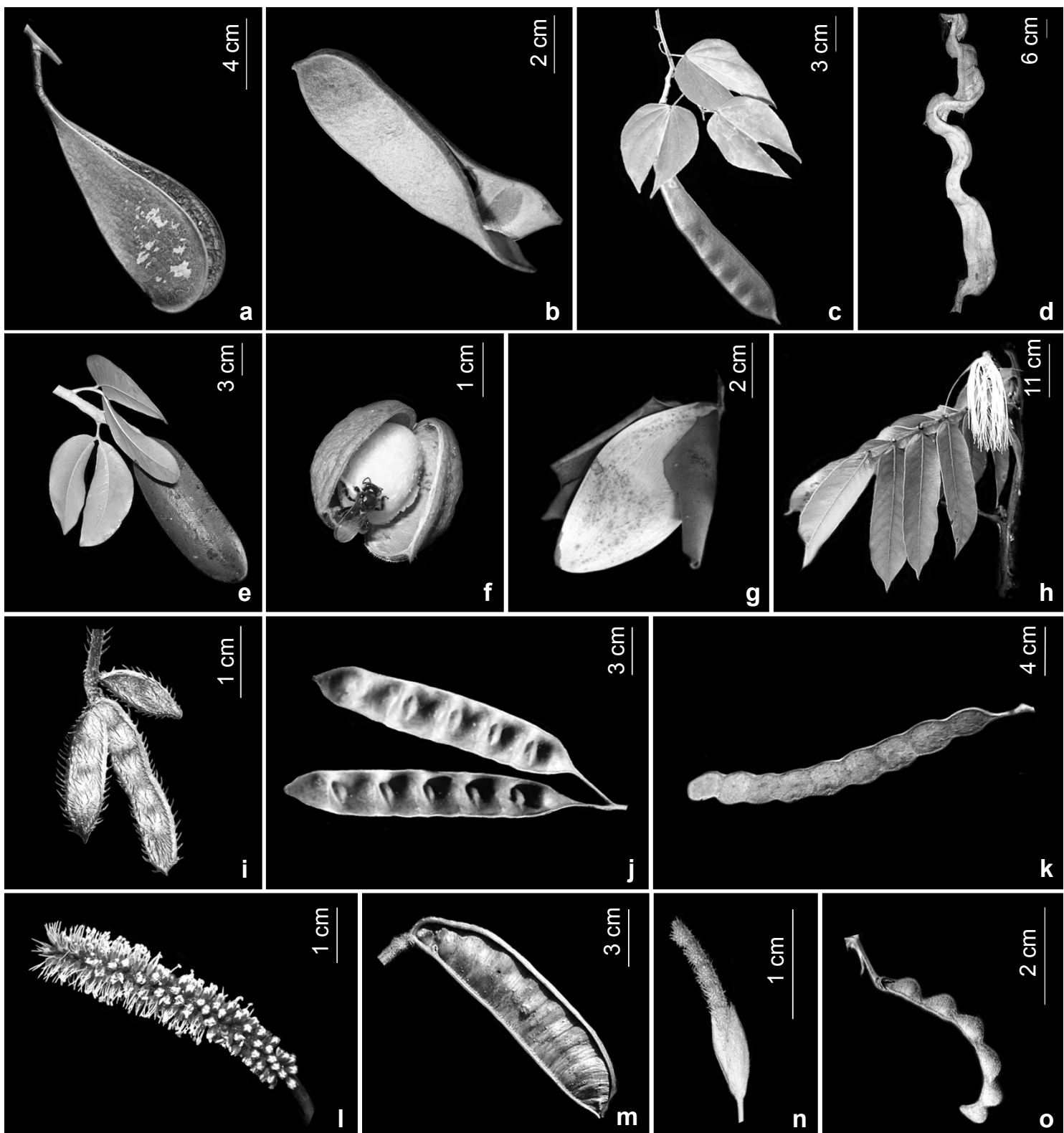

$\mid$
k
o
o

Figura 3 - a. Schizolobium parahyba (Silva 546); b. Poincianella pluviosa (Silva 1207); c. Bauhinia forficata (Silva 1122); d. Phanera angulosa (Silva 647); e. Hymenaeae courbaril (Silva 1194); f. Copaifera langsdorffii (Silva 1030); g. Tachigali denudata (Scobar 154); h. Inga sessilis (Silva 366); i. Mimosa diplotricha (Silva 1111); j. Piptadenia adiantoides (Silva 1146); k. Anadenanthera colubrina (Silva 1155); 1. Pseudopiptadenia leptostachya (Silva 1040); m. Albizia pedicellaris (Silva 315); n. Zornia curvata (Silva 1081); o. Desmodium uncinatum (Silva 764).

Figure 3 - a. Schizolobium parahyba (Silva 546); b. Poincianella pluviosa (Silva 1207); c. Bauhinia forficata (Silva 1122); d. Phanera angulosa (Silva 647); e. Hymenaeae courbaril (Silva 1194); f. Copaifera langsdorffii (Silva 1030); g. Tachigali denudata (Scobar 154); h. Inga sessilis (Silva 366); i. Mimosa diplotricha (Silva 1111); j. Piptadenia adiantoides (Silva 1146); k. Anadenanthera colubrina (Silva 1155); 1. Pseudopiptadenia leptostachya (Silva 1040); m. Albizia pedicellaris (Silva 315); n. Zornia curvata (Silva 1081); o. Desmodium uncinatum (Silva 764). 
3.1 Copaifera langsdorffii Desf., Mem. Mus. Hist. Nat. 7: 377. 1821.

Material selecionado: BRASIL. SÃO PAULO: Ubatuba, Parque Estadual da Serra do Mar, Fazenda Capricórnio, 23.V.2008, E.D. Silva 1030 (UEC).

Distribuição geográfica: América do Sul. Brasil (todas as regiões).

Domínio fitogeográfico brasileiro: Amazônia, Caatinga, Cerrado e Mata Atlântica.

3.2 Copaifera trapezifolia Hayne, Getreue Darstell. Gew. 23. 1825.
Material selecionado: BRASIL. SÃO PAULO: Ubatuba, Parque Estadual da Serra do Mar, Fazenda Capricórnio, 11.VII.2007, E.D. Silva 883 (UEC).

Distribuição geográfica: América do Sul. Brasil (Sul, Sudeste e Nordeste).

Domínio fitogeográfico brasileiro: Amazônia, Caatinga, Cerrado, Mata Atlântica, Pampa e Pantanal.

4. Phanera Lour., Fl. Cochinch. 1: 37. 1790.

1. Ramos jovens com gavinhas duplas, folhas dimórficas, fruto legume P. angulosa

1'. Ramos jovens com gavinhas simples, folhas não dimórficas, legume samaróide ....... P. microstachya

4.1. Phanera angulosa (Vogel) Vaz, Rodriguésia 61: 36. 2010.

Material selecionado: BRASIL. SÃO PAULO: Ubatuba, Parque Estadual da Serra do Mar, Fazenda Capricórnio, 28.I.2007, fr., E.D. Silva 647 (UEC).

Distribuição geográfica: Endêmica do Brasil (Sul, Sudeste e Nordeste).

Domínio fitogeográfico brasileiro: Mata Atlântica.

4.2 Phanera microstachya (Raddi) L.P. Queiroz, Neodiversity 1(1): 6. 2006.

Material selecionado: BRASIL. SÃO PAULO: Ubatuba, Parque Estadual da Serra do Mar, Fazenda Capricórnio, 26.I.2008, E.D. Silva 1035 (UEC).

Distribuição geográfica: América Central e do Sul. Brasil (todas as regiões).

Domínio fitogeográfico brasileiro: Amazônia, Caatinga e Mata Atlântica.

5. Poincianella Britton \& Rose, N. Amer. Fl. 23(5): 327. 1930. Referência: Ulibarri 1996, Queiroz 2009.

5.1 Poincianella pluviosa (DC.) L. P. Queiroz, Legum. Caatinga 126. 2009.
Material selecionado: BRASIL. SÃO PAULO: Núcleo Santa Virgínia, Parque Estadual da Serra do Mar, 16.X.2006, fl., E.D. Silva 769 (UEC).

Distribuição geográfica: América do Sul. Brasil (todas as regiões).

Domínio fitogeográfico brasileiro: Amazônia, Caatinga, Cerrado, Mata Atlântica e Pantanal.

6. Hymenaea L., Sp. Pl. 2: 1192. 1753.

6.1 Hymenaea courbaril L., Sp. Pl. 2: 1192. 1753.

Material selecionado: BRASIL. SÃO PAULO: Ubatuba, Parque Estadual da Serra do Mar, Fazenda Capricórnio, 10.I.2007, fl., E.D. Silva 1045 (UEC).

Distribuição geográfica: Pantropical. Brasil (todas as regiões).

Domínio fitogeográfico brasileiro: Amazônia, Caatinga, Cerrado, Mata Atlântica e Pantanal.

7. Senna Mill., Gard. Dict. Abr. 4. 1754.

Referências: Irwin \& Barneby 1982a, 1982b; Rodrigues et al. 2005.

\section{Chave de identificação das espécies de Senna no Parque Estadual da Serra do Mar, São Paulo}

1. Arbustos; folhas com 4 pares de folíolos S. tropica

1'. Árvores; folhas com 2 ou10-20 pares de folíolos

2. Folhas com 2 pares de folíolos; folíolos assimétricos, falcado-lanceolados, 6,5-14 cm compr., com a face adaxial glabra; flores 3,5-4 cm compr ..... S. macranthera

2'. Folhas com 10 a 20 pares de folíolos; folíolos oblongos, oblongo-elípticos ou obovados, $2-4 \mathrm{~cm}$ compr., pubérulos em ambas as faces; flores 1,5-1,8 cm compr S. multijuga

7.1. Senna macranthera (DC. ex Collad.) H.S. Irwin \& Barneby, Mem. New York Bot. Gard. 35: 181. 1982.
Material selecionado: BRASIL. SÃO PAULO: Ubatuba, Parque Estadual da Serra do Mar, Fazenda Capricórnio, 10.III.2007, fl., E.D. Silva 709 (UEC, MBM, RB). 
Distribuição geográfica: América do Sul. Brasil (todas as regiões).

Domínio fitogeográfico brasileiro: Amazônia, Caatinga, Cerrado, Mata Atlântica e Pantanal.

7.2. Senna multijuga (Rich.) H.S. Irwin \& Barneby, Mem. New York Bot. Gard. 35: 492. 1982.

Material selecionado: BRASIL. SÃO PAULO: Núcleo Santa Virgínia, Parque Estadual da Serra do Mar, 11.III.2007, fl., E.D. Silva 712 (UEC, MBM).

Distribuição geográfica: Pantropical. Brasil (todas as regiões).

Domínio fitogeográfico brasileiro: Amazônia, Caatinga, Cerrado e Mata Atlântica.

7.3. Senna tropica (Vell.) H.S. Irwin \& Barneby, Mem. New York Bot. Gard. 35: 368. 1982.

Espécie de difícil identificação pela semelhança que apresenta com Senna septemtrionalis (Viv.) H. S. Irwin \& Barneby e $S$. araucarietorum H. S. Irwin \& Barneby.

Irwin \& Barneby (1982a) separam Senna tropica de S. septemtrionalis e de $S$. araucarietorum pela presença de anteras com ápice proeminentemente 2-umbonado, ovário 66-96-ovulado e sementes bisseriadas.

Apesar de considerarmos o táxon encontrado como sendo $S$. tropica, estudos recentes que apontem para a correta separação dessas espécies ainda são necessários.

Material examinado: BRASIL. SÃO PAULO: Núcleo Santa Virgínia, Parque Estadual da Serra do Mar, 17.XI.2007, fl., E.D. Silva 987 (UEC).

Distribuição geográfica: Endêmica do Brasil (Sul e Sudeste).
Domínio fitogeográfico brasileiro: Mata Atlântica.

8. Schizolobium Vogel, Linnaea 11: 399. 1837.

8.1. Schizolobium parahyba (Vell.) S.F. Blake, Contr. U.S. Natl. Herb. 20(7): 240. 1919.

Material selecionado: BRASIL. SÃO PAULO: Ubatuba, Parque Estadual da Serra do Mar, Fazenda Capricórnio, 7.09.2006, fr., E.D. Silva 546 (UEC).

Distribuição geográfica: Pantropical. Brasil (Sul, Sudeste, Norte e Nordeste).

Domínio fitogeográfico brasileiro: Amazônia e Mata Atlântica.

9. Tachigali Aubl., Hist. Pl. Guiane 372 (t. 143). 1775. Referência: Dwyer 1958.

9.1. Tachigali denudata (Vogel) Oliveira-Filho, Cat. Árvores Nativas Minas Gerais, 140. 2006.

Material selecionado: BRASIL. SÃO PAULO: Ubatuba, Parque Estadual da Serra do Mar, Fazenda Capricórnio, parcela G, 7.11.2006, J. A. M. A. Gomes 438 (UEC).

Distribuição geográfica: Endêmica do Brasil (Sul e Sudeste).

Domínio fitogeográfico brasileiro: Mata Atlântica.

\section{Subfamília Mimosoideae}

$\mathrm{Na}$ área de estudo foram encontradas 27 espécies de Mimosoideae pertencentes a oito gêneros e três tribos, sendo 21 de hábito arbóreo, duas subarbustivo-arbustivo e quatro lianas. Seus gêneros podem ser reconhecidos a partir da chave apresentada a seguir, na qual estão ilustrados os principais caracteres diagnósticos (Fig. 3h-m):

\section{Chave para os gêneros de Mimosoideae no Parque Estadual da Serra do Mar, São Paulo}

1. Folhas pinadas, nectário foliar entre todos os pares de folíolos Inga

1'. Folhas bipinadas, nectário foliar no pecíolo e/ou entre alguns pares de foliólulos.

2. Androceu até 10 estames livres.

3. Fruto craspédio Mimosa

3'. Outro tipo de fruto, não craspédio.

4. Legumes com valvas membranáceas ou papiráceas, não lenhosas, com ambas as margens retas ou quase Piptadenia

4'. Legumes com valvas coriáceas, com ambas ou pelo menos uma das margens onduladas, ou folículo.

5. Inflorescência em glomérulos globosos; fruto folículo, margens levemente constritas entre as sementes Anadenanthera

5'. Inflorescência em espigas cilíndricas ou subglobosas; fruto legume, pelo menos uma margem muito constrita entre as sementes Pseudopiptadenia

2'. Androceu mais de 10 estames.

6. Árvores; ramos inermes; fruto folículo ou legume com valvas torcidas ou espiraladas 
7. Folículo lenhoso, com estrias transversais, endocarpo não avermelhado, valvas retas, semente com funículo caduco Albizia

7'. Legume coriáceo, sem estrias transversais, endocarpo avermelhado, valvas torcidas ou espiraladas, semente com funículo persistente Abarema

6'. Lianas; ramos aculeados, legume com valvas retas Senegalia

1. Abarema Pittier, Trab. Mus. Comercial Venezuela. 86. 1927. Referência: Barneby \& Grimes 1996, Iganci \& Morim 2012.

1.1 Abarema langsdorffii (Benth.) Barneby \& J.W. Grimes, Mem. New York Bot. Gard. 74(1): 95. 1996.

Material selecionado: BRASIL. SÃO PAULO. Núcleo Santa Virgínia, Parque Estadual da Serra do Mar, 17.XI.2007, fl., E.D. Silva 990 (UEC, MBM, RB).

Distribuição geográfica: Endêmica do Brasil (Sul, Sudeste e Nordeste).

Domínio fitogeográfico brasileiro: Mata Atlântica.

2. Albizia Durazz., Mag. Tosc. 3(4): 13. 1772. Referência: Barneby \& Grimes 1996.

2.1. Albizia pedicellaris (DC.) L. Rico, Novon 9(4): 555. 1999.

Material selecionado: BRASIL. SÃO PAULO: Ubatuba, Parque Estadual da Serra do Mar, Fazenda
Capricórnio, 28.I.2007, fl., E.D. Silva 649 (UEC, MBM). Distribuição geográfica: América do Sul. Brasil (todas as regiões).

Domínio fitogeográfico brasileiro: Amazônia, Cerrado e Mata Atlântica.

3. Anadenanthera Speg., Physis. (Buenos Aires) 6: 313. 1923. Referência: Altschul 1964.

3.1. Anadenanthera colubrina (Vell.) Brenan, Kew Bull. 10(2): 182. 1955.

Material selecionado: BRASIL. SÃO PAULO: Núcleo Santa Virgínia, Parque Estadual da Serra do Mar, 24.V.2008, fr., E.D. Silva 1155 (UEC).

Distribuição geográfica: América do Sul. Brasil (Sul, Sudeste, Norte e Nordeste).

Domínio fitogeográfico brasileiro: Caatinga, Cerrado e Mata Atlântica.

4. Inga Mill., Gard. Dict. Abrid. 2: (4). 1754. Referências: Pennington 1997, Garcia 1998.

\section{Chave de identificação das espécies de Inga no Parque Estadual da Serra do Mar, São Paulo}

1. Folíolos glabros a levemente pubérulos.

2. Folhas com 5-9 pares de folíolos, fruto espiralado I. schinifolia

2'. Folhas com 2-4 pares de folíolos, fruto reto a encurvado.

3. Raque foliar alada, inflorescência cilíndrica I. marginata

3'. Raque foliar cilíndrica a marginada, inflorescência subglobosa a globosa .

4. Folhas 2(3) pares de folíolos, cálice 3-9 mm compr., flores sésseis I. capitata

4'. Folhas 2-4 pares de folíolos, cálice 1-2,5 mm compr., flores pediceladas (2-3 mm compr.), I. lanceifolia

1'. Folíolos tomentosos a híspidos, pelo menos em uma das faces.

5. Raque foliar cilíndrica ou levemente alada no ápice (raro), ovário 1-2 carpelos I. hispida

5'. Raque foliar alada, ovário unicarpelar.

6. Nectário longo estipitado (3-6 $\mathrm{mm}$ compr.) I. barbata

6'. Nectário séssil a curto estipitado (até $1,5 \mathrm{~mm}$ compr.).

7. Nectário comprimido transversalmente, frutos longo-cilíndricos I. edulis

7'. Nectário não comprimido transversalmente, frutos plano-compressos a retangulares

8. Cálice estriado, glabrescente, fruto com margens expandidas, estrias longitudinais presentes, conspícuas I. striata

8'. Cálice sem estrias, piloso, fruto com margens não expandidas, estrias longitudinais ausentes ou, se presentes, inconspícuas.

9. Flores $8 \mathrm{~cm}$ compr., fruto muito encurvado, denso-velutino I. sessilis

9'. Flores até $3 \mathrm{~cm}$ compr., fruto reto a levemente encurvado, glabro, tomentoso ou híspido 10. Folíolos tomentosos em ambas as faces, fruto glabro a tomentoso I. mendoncaei 10'. Folíolos glabros a glabrescentes na face adaxial, fruto híspido .... I. vulpina 
4.1. Inga barbata Benth., London J. Bot. 4: 605. 1845.

Inga barbata é muito semelhante à Inga vulpina, inclusive quando em estado reprodutivo. Pennington (1997) separa as duas espécies a partir do número de folíolos, tamanho das estípulas e tamanho do cálice e corola.

As principais diferenças observadas entre Inga barbata e Inga vulpina na área estudada estão relacionadas ao tamanho e forma das estípulas, tamanho do nectário, tamanho das flores e indumento do cálice. Inga barbata apresenta estípulas com 6-8 mm compr., largo-lanceoladas, nectário longo-estipitado (3-6 mm compr.), flores 2,5-3 cm compr. e cálice subglabro, enquanto Inga vulpina possui estípulas com $4 \mathrm{~mm}$ compr., oblongas, nectário séssil a curto-estipitado (1 $\mathrm{mm}$ compr.), flores $1,5-2,5 \mathrm{~cm}$ compr. e cálice adpresso-piloso.

Material selecionado: BRASIL. SÃO PAULO: Núcleo Santa Virgínia, Parque Estadual da Serra do Mar, 22.V.2008, fr., E.D. Silva 1112 (UEC, MBM, RB).

Distribuição geográfica: Endêmica do Brasil (Sul e Sudeste).

Domínio fitogeográfico brasileiro: Mata Atlântica.

4.2. Inga capitata Desv., J. Bot. Agric. 3: 71. 1814.

Material selecionado: BRASIL. SÃO PAULO: Ubatuba, Parque Estadual da Serra do Mar, Fazenda Capricórnio, 11.VIII.2007, E.D. Silva 882 (UEC).

Distribuição geográfica: América do Sul. Brasil (Sudeste, Norte e Nordeste).

Domínio fitogeográfico brasileiro: Amazônia e Mata Atlântica.

4.3. Inga edulis Mart., Flora 20(2): 113. 1837. Material selecionado: BRASIL. SÃO PAULO: Núcleo Santa Virgínia, Parque Estadual da Serra do Mar, 17.XI.2007, fr., E.D. Silva 983 (UEC).

Distribuição geográfica: Pantropical. Brasil (todas as regiões).

Domínio fitogeográfico brasileiro: Amazônia, Caatinga, Cerrado e Mata Atlântica.

4.4 Inga hispida Schott ex Benth., Trans. Linn. Soc. London 30(3): 625. 1875.

Material selecionado: BRASIL. SÃO PAULO: Núcleo Santa Virgínia, Parque Estadual da Serra do Mar, 7.IX.2008, fl., E.D. Silva 1169 (UEC, MBM, $\mathrm{RB})$.

Distribuição geográfica: Endêmica do Brasil (Sudeste e Nordeste).

Domínio fitogeográfico brasileiro: Mata Atlântica.
4.5. Inga lanceifolia Benth., Trans. Linn. Soc. London 30: 606. 1875.

Material selecionado: BRASIL. SÃO PAULO: Núcleo Santa Virgínia, Parque Estadual da Serra do Mar, 7.IX.2008, fr., E.D. Silva 1170 (UEC, MBM, RB).

Distribuição geográfica: Endêmica do Brasil (Sudeste). Domínio fitogeográfico brasileiro: Mata Atlântica.

4.6. Inga marginata Willd., Sp. Pl., 4(2): 1015. 1806.

Material selecionado: BRASIL. SÃO PAULO: Núcleo Santa Virgínia, Parque Estadual da Serra do Mar, 11.III.2007, fl., E.D. Silva 711 (UEC).

Distribuição geográfica: América Central e do Sul. Brasil (todas as regiões).

Domínio fitogeográfico brasileiro: Amazônia, Cerrado e Mata Atlântica.

4.7. Inga mendoncaei Harms, Notizbl. Konigl. Bot. Gart. Berlin 6: 300. 1915.

Material selecionado: BRASIL. SÃO PAULO: Ubatuba, Parque Estadual da Serra do Mar, Fazenda Capricórnio, 9.IX.2007, fr., E.D. Silva 951 (UEC, MBM). Distribuição geográfica: Endêmica do Brasil (Sudeste). Domínio fitogeográfico brasileiro: Mata Atlântica.

4.8. Inga schinifolia Benth., London J. Bot. 4: 584. 1845.

Devido ao número e a forma dos folíolos pode ser confundida com Inga tenuis (Vell.) Mart., quando em estado vegetativo, no entanto, Inga schinifolia possui frutos espiralados e Inga tenuis frutos retos. Material selecionado: BRASIL. SÃO PAULO: Ubatuba, Parque Estadual da Serra do Mar, Fazenda Capricórnio, s.d., fr., E.D. Silva 877 (UEC).

Distribuição geográfica: Endêmica do Brasil (Sudeste). Domínio fitogeográfico brasileiro: Mata Atlântica.

4.9. Inga sessilis (Vell.) Mart., Flora 20(2): 114. 1837. Material selecionado: BRASIL. SÃO PAULO: Núcleo Santa Virgínia, Parque Estadual da Serra do Mar, 19.VII.2006, fl. e fr., E.D. Silva 366 (UEC).

Distribuição geográfica: América do Sul. Brasil (Sul, Sudeste, Norte, Nordeste).

Domínio fitogeográfico brasileiro: Amazônia, Cerrado e Mata Atlântica.

4.10. Inga striata Benth., London J. Bot. 4: 608. 1845. Material selecionado: BRASIL. SÃO PAULO: Núcleo Santa Virgínia, Parque Estadual da Serra do Mar, 17.XI.2007, fr., E.D. Silva 985 (UEC, MBM).

Distribuição geográfica: América do Sul. Brasil (Sul, Sudeste e Nordeste).

Domínio fitogeográfico brasileiro: Amazônia, Cerrado e Mata Atlântica. 
4.11. Inga vulpina Mart. ex Benth., Trans. Linn. Soc. London 30(3): 625. 1875.

Material selecionado: BRASIL. SÃO PAULO: Núcleo Santa Virgínia, Parque Estadual da Serra do Mar, 8.IX.2008, fl. e fr., E.D. Silva 1178 (UEC).
Distribuição geográfica: Endêmica do Brasil (Sul, Sudeste e Nordeste).

Domínio fitogeográfico brasileiro: Cerrado e Mata Atlântica.

5. Mimosa L., Sp. Pl. 1: 516. 1753. Referência: Barneby 1991.

\section{Chave de identificação das espécies de Mimosa no Parque Estadual da Serra do Mar, São Paulo}

1. Árvore.

2. Ramos inermes, ásperos, indumento formado por tricomas estrelados e/ou setosos; flores amarelas, fruto rugoso M. scabrella

2'. Ramos aculeados, lanosos a subglabros, flores brancas, fruto liso.

3. Pecíolo 0,8-1,4 cm compr., foliólulos 15-25 pares, oblongo-lineares, 5-11 × 0,8-1,8 mm, presos à raque com a sua porção lateral, face abaxial glabra M. bimucronata

3'. Pecíolo 1,5-2,5 cm compr., foliólulos 8-14 pares, oblongos a assimétricos, 8-11 $\times 3-5 \mathrm{~mm}$, presos à raque com a sua porção central, face abaxial adpresso-pilosa

Mimosa aff. bimucronata

1'. Subarbusto a arbusto.

4. Folhas com 6 a 8 pares de pinas, foliólulos 16-21 pares, ramos pilosos a glabros, acúleos enfileirados M. diplotricha

4'. Folhas com 1 par de pinas, foliólulos 27-29 pares, ramos com indumento de tricomas híspidoamarronzados, longos, alternando com tricomas levemente tomentoso-esbranquiçados, curtos; acúleos dispersos M. ramosissima

5.1. Mimosa bimucronata (DC.) Kuntze, Gen. Pl. 1: 198.1891.

Material selecionado: BRASIL. SÃO PAULO. Núcleo Santa Virgínia, Parque Estadual da Serra do Mar, 11.III.2007, fl., E.D. Silva 713 (UEC).

Distribuição geográfica: Pantropical. Brasil (Sul, Sudeste, Centro-Oeste, Norteste).

Domínio fitogeográfico brasileiro: Cerrado e Mata Atlântica.

5.2. Mimosa diplotricha Wright in Sauvalle, Anales Acad. Ci. Med 5: 405. 1868.

Material selecionado: BRASIL. SÃO PAULO. Núcleo Santa Virgínia, Parque Estadual da Serra do Mar, 22.V.2008, fl. e fr., E.D. Silva 1111 (UEC, MBM, RB).

Distribuição geográfica: Pantropical. Brasil (todas as regiões).

Domínio fitogeográfico brasileiro: Amazônia, Cerrado e Mata Atlântica.

5.3. Mimosa ramosissima Benth., Trans. Linn. Soc. London 30(3): 394. 1875.

Material selecionado: BRASIL. SÃO PAULO: Núcleo Santa Virgínia, Parque Estadual da Serra do Mar, 10.IX.2006, fr., E.D. Silva 392 (UEC, MBM, RB).
Distribuição geográfica: Endêmica do Brasil (Sul e Sudeste).

Domínio fitogeográfico brasileiro: Mata Atlântica.

5.4. Mimosa scabrella Benth., J. Bot., 4(31): 387. 1841.

Material selecionado: BRASIL. SÃO PAULO: Núcleo Santa Virgínia, Parque Estadual da Serra do Mar, 18.VII.2006, fl. e fr., E.D. Silva 364 (UEC, MBM, RB). Distribuição geográfica: Endêmica Brasil (Sul e Sudeste).

Domínio fitogeográfico brasileiro: Mata Atlântica.

5.5. Mimosa aff. bimucronata (DC.) Kuntze, Gen. Pl. 1: 198. 1891.

Espécime com algumas características morfológicas semelhantes a $M$. bimucronata, mas a ausência de material com flores não permitiu a determinação definitiva ao nível específico.

Material selecionado: BRASIL. SÃO PAULO. Núcleo Santa Virgínia, Parque Estadual da Serra do Mar, 19.VII.2006, fr., E.D. Silva 369 (UEC).

6. Piptadenia Benth., J. Bot. 2: 135. 1840. Referência: Tamashiro 1989. 
Chave de identificação das espécies de Piptadenia no Parque Estadual da Serra do Mar, São Paulo

1. Lianas ou arvoretas escandentes, inflorescências avermelhadas P. adiantoides

1'. Árvores, inflorescências branco-amareladas.

2. Caule com cristas longitudinais conspícuas; ramos geralmente aculeados; foliólulos 30-49 pares, linear-falcados, 4-9 × 0,8-1 mm; ovário glabro; legumes 9-16 × 2-2,3 cm ..... P. gonoacantha

2'. Caule sem cristas longitudinais; ramos geralmente inermes; foliólulos 5-9 pares, 1,8-4,4 $\times 0,9-1,9$ cm, falcado-lanceolados; ovário piloso; legumes 18,5-23 × 2,5-3,9 cm P. paniculata

6.1. Piptadenia adiantoides (Spreng.) J. F. Macbr., Contr. Gray Herb. 59: 17. 1919.

Material selecionado: BRASIL. SÃO PAULO: Núcleo Santa Virgínia, Parque Estadual da Serra do Mar, 24.V.2008, fr., E.D. Silva 1146 (UEC, MBM).

Distribuição geográfica: América do Sul. Brasil (Sudeste, Norte e Nordeste).

Domínio fitogeográfico brasileiro: Caatinga, Cerrado e Mata Atlântica.

6.2. Piptadenia gonoacantha (Mart.) J. F. Macbr., Contr. Gray Herb. 59: 17. 1919.

Material selecionado: BRASIL. SÃO PAULO: Ubatuba, Parque Estadual da Serra do Mar, Fazenda Capricórnio, 28.I.2007, fl., E.D. Silva 653 (UEC).
Distribuição geográfica: Améria do Sul. Brasil (Sul, Sudeste, Centro-Oeste e Nordeste).

Domínio fitogeográfico brasileiro: Cerrado e MataAtlântica.

6.3. Piptadenia paniculata Benth., J. Bot. 4(31): 338. 1841.

Material selecionado: BRASIL. SÃO PAULO: Núcleo Santa Virgínia, Parque Estadual da Serra do Mar, 27.I.2007, fl., E.D. Silva 631 (UEC, MBM).

Distribuição geográfica: Endêmica do Brasil (Sul, Sudeste e Nordeste).

Domínio fitogeográfico brasileiro: Cerrado e MataAtlântica.

7. Pseudopiptadenia Rauschert, Taxon 31(3): 559. 1982. Referência: Lewis \& Lima 1991.

\section{Chave de identificação das espécies de Pseudopiptadenia no Parque Estadual da Serra do Mar, São Paulo}

1. Folhas com 2-4 pares de pinas; foliólulos 5-11 pares, 1-2,9 ×0,4-1 cm, glabros em ambas as faces; frutos 1,1-1,4 cm larg., encurvados, estipitados ( $5 \mathrm{~mm}$ compr.) P. leptostachya

1'. Folhas com 5-8 pares de pinas; foliólulos 10-25 pares, 4-11 $\times 1-3 \mathrm{~mm}$, face abaxial levemente adpressopilosa; frutos retos, 3,3-4 cm larg., longo-estipitados (4,5 cm compr.) P. warmingii

\subsection{Pseudopiptadenia leptostachya (Benth.) Rauschert, Taxon 31(3): 559. 1982. \\ Material selecionado: BRASIL. SÃO PAULO: Núcleo Santa Virgínia, Parque Estadual da Serra do Mar, 24.V.2008, fr., E.D. Silva 1158 (UEC). \\ Distribuição geográfica: Endêmica do Brasil (Sudeste). Domínio fitogeográfico brasileiro: Mata Atlântica.}

7.2. Pseudopiptadenia warmingii (Benth.) G.P. Lewis \& M.P. Lima, Arquivos do Jardim Botânico do Rio de Janeiro 30: 54. 1991.
Material selecionado: BRASIL. SÃO PAULO: Ubatuba, Parque Estadual da Serra do Mar, Fazenda Capricórnio, 23.V.2008, E.D. Silva 1138 (UEC).

Distribuição geográfica: Endêmica do Brasil (Sul, Sudeste e Nordeste).

Domínio fitogeográfico brasileiro: Mata Atlântica.

8. Senegalia Raf., Sylva Tellur. 119. 1838.

Referências: Seigler et al. 2006, Rico-Arce 2007, Barros 2011.

\section{Chave de identificação das espécies de Senegalia no Parque Estadual da Serra do Mar, São Paulo}

1. Inflorescência espiga cilíndrica S. lacerans

1'. Inflorescência espiga subglobosa.

2. Foliólulos com nervura principal muito excêntrica; ovário denso-piloso S. paniculata

2'. Foliólulos com nervura principal central ou levemente excêntrica; ovário glabro a levemente piloso S. martiusiana 
8.1. Senegalia lacerans (Benth.) Seigler \& Ebinger, Phytologia 88(1): 55. 2006.

Material selecionado: BRASIL. SÃO PAULO: Núcleo Santa Virgínia, Parque Estadual da Serra do Mar, 26.I.2007, fl., E.D. Silva 629 (UEC, MBM, RB).

Distribuição geográfica: Endêmica do Brasil (Sul, Sudeste e Nordeste).

Domínio fitogeográfico brasileiro: Mata Atlântica.

8.2. Senegalia tenuifolia Britton \& Rose, N. Amer. Fl. 23(2): 118. 1928.

Material selecionado: BRASIL. SÃO PAULO: Ubatuba, Parque Estadual da Serra do Mar, Fazenda Capricórnio, 23.II.2008, fl., E.D. Silva 1096 (UEC, MBM).

Distribuição geográfica: Endêmica do Brasil (todas as regiões).

Domínio fitogeográfico brasileiro: Amazônia, Caatinga, Cerrado e Mata Atlântica.
8.3. Senegalia martiusiana (Steud.) Bocage \& L.P. Queiroz, Neodiversity 1(2): 12. 2006

Material selecionado: BRASIL. SÃO PAULO: Núcleo Santa Virgínia, Parque Estadual da Serra do Mar, 19.VII.2006, fr., E.D. Silva 365 (UEC).

Distribuição geográfica: Endêmica do Brasil (Nordeste, Centro-Oeste, Sudeste).

Domínio fitogeográfico brasileiro: Caatinga e Mata Atlântica.

\section{Subfamília Papilionoideae}

Na área de estudo foram encontradas 39 espécies pertencentes a 18 gêneros e sete tribos, sendo $15 \mathrm{de}$ hábito arbóreo, 13 subarbustivo-arbustivo e 11 lianas. Seus gêneros podem ser reconhecidos a partir da chave apresentada a seguir, na qual estão ilustrados os principais caracteres diagnósticos (Figs. 3o-n, 4a-o):

\section{Chave para os gêneros de Papilionoideae no Parque Estadual da Serra do Mar, São Paulo}

1. Folhas simples, unifolioladas a trifolioladas.

2. Fruto lomento.

3. Folhas bifolioladas, lomento aculeado

Zornia

3'. Folhas trifolioladas, lomento sem acúleos.

4. Estípulas com ápice bipartido; Inflorescência congesta, flores amarelas; fruto inconspícuo com apenas um artículo fértil Stylosanthes

4'. Estípulas com ápice não bipartido; Infloresência laxa, flores róseas, azuladas ou lilases; fruto conspícuo com mais de um artículo fértil Desmodium

2'. Fruto legume ou drupa.

5. Árvore; fruto drupa Zollernia

5'. Arbusto subarbusto ou liana; fruto legume.

6. Legume subinflado a fortemente inflado.

7. Anteras uniformes, fruto com septos oblíquos entre as sementes Cajanus

7'. Anteras dimorfas, fruto sem septos oblíquos entre as sementes Crotalaria

6'. Legume com outras características.

8. Legume linear, carena com ápice fortemente tubuloso, estilete barbado Cochliasanthus

8'. Legume oblongo, largo-oblongo ou semi-orbicular, ápice da carena não tubuloso ou levemente tubuloso, estilete não barbado.

9. Legume com estrias longitudinais salientes e indumento de tricomas urticantes, inflorescência pêndula, pedúnculo flexível Mucuna

9'. Legume sem estrias longitudinais salientes, glabros ou com indumento não urticante, inflorescência ereta a subereta, pedúnculo rígido Dioclea

1'. Folhas pinadas.

10. Corola não papilionácea, formada por 5 pétalas semelhantes entre si, ou reduzida a uma pétala vexilar ou apétala.

11. Folíolos com glândulas, fruto sâmara Myrocarpus

11'. Folíolos sem glândulas, fruto nucóide Swartzia

10'. Corola papilionácea formada por 5 pétalas diferentes entre si.

12. Fruto sâmara ou legume samaróide.

13. Fruto sâmara.

14. Sâmara com ala apical, ramos aculeados ou inermes Machaerium 

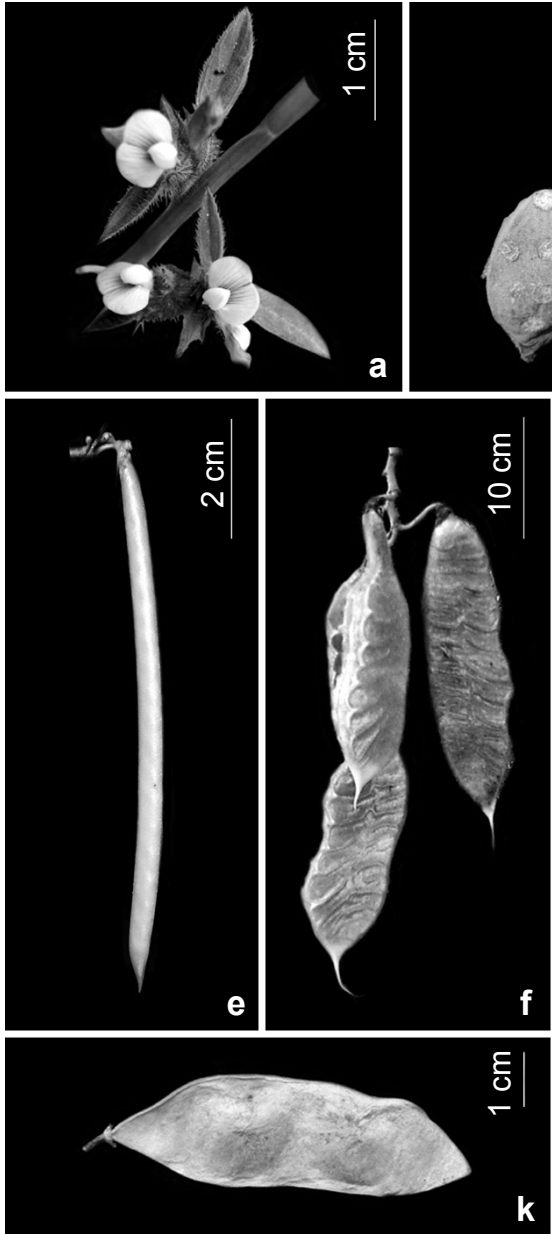

k

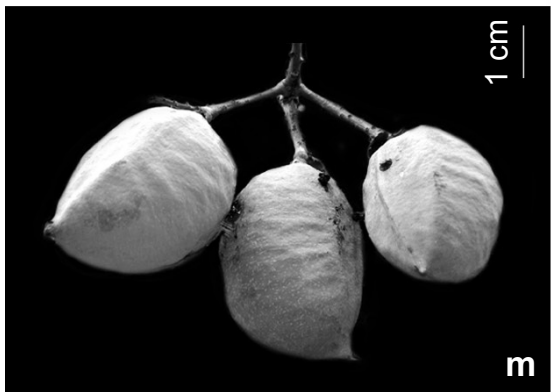

$\mathbf{m}$
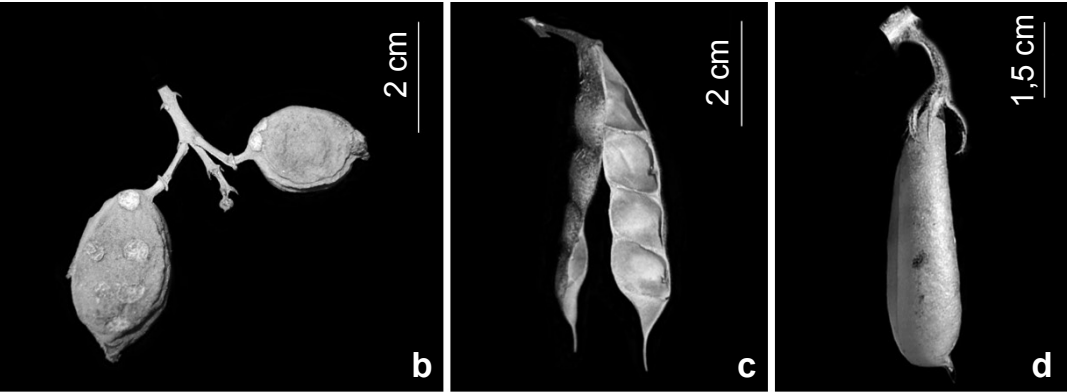

g
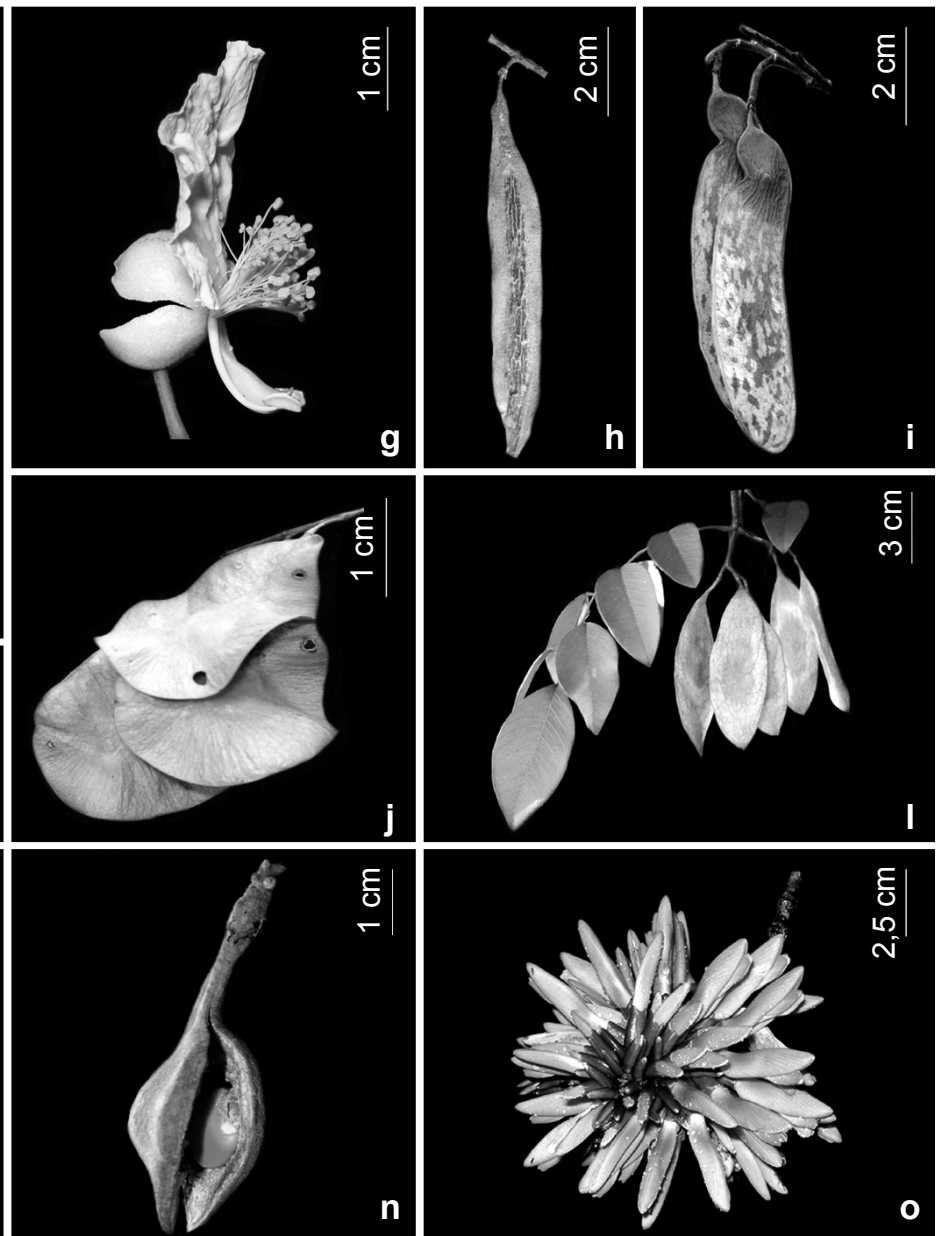

Figura 4 - a. Stylosanthes guianensis (Silva 1154); b. Zollernia ilicifolia (Silva \& Piacentini 374); c. Cajanus cajan (Santos 577); d. Crotalaria junceae (Silva 1148); e. Cochliasanthus caracalla (Silva 1210); f. Mucuna urens (Silva 335); g. Swartzia langsdorffii (Silva 1082); h. Myrocarpus frondosus (Dias et al. 44); i. Machaerium nictitans (Silva 1156); j. Pterocarpus rohrii (Silva 486); k. Lonchocrpus cultratus (Aguirre et al. 68); 1. Dalbergia frutescens (Silva 1110); m. Andira fraxinifolia (Silva 835); n. Ormosia arborea (Figueiredo \& Rodrigues 14403); o. Dahlstedtia pinnata (Silva 708).

Figure 4 - a. Stylosanthes guianensis (Silva 1154); b. Zollernia ilicifolia (Silva \& Piacentini 374); c. Cajanus cajan (Santos 577); d. Crotalaria junceae (Silva 1148); e. Cochliasanthus caracalla (Silva 1210); f. Mucuna urens (Silva 335); g. Swartzia langsdorffii (Silva 1082); h. Myrocarpus frondosus (Dias et al. 44); i. Machaerium nictitans (Silva 1156); j. Pterocarpus rohrii (Silva 486); k. Lonchocrpus cultratus (Aguirre et al. 68); 1. Dalbergia frutescens (Silva 1110); m. Andira fraxinifolia (Silva 835); n. Ormosia arborea (Figueiredo \& Rodrigues 14403); o. Dahlstedtia pinnata (Silva 708). 
14'. Sâmara com ala circular, ramos inermes Pterocarpus

13'. Legume samaróide.

15. Folíolos opostos, fruto com nervuras marginais proeminentes Lonchocarpus

15'. Folíolos subopostos a alternos, frutos sem nervuras marginais Dalbergia

12'. Fruto drupáceo, legume ou legume nucóide.

16. Fruto drupáceo ou legume com valvas côncavas e semente bicolor, corola não tubulosa

17. Fruto drupáceo, semente com uma única cor Andira

17'. Legume com valvas côncavas, semente bicolor Ormosia

16'. Legume nucóide; corola tubulosa Dahlstedtia

1. Andira Juss., Gen. Pl. 363. 1789. Referência:

Pennington 2003.

\section{Chave de identificação das espécies de Andira no Parque Estadual da Serra do Mar, São Paulo}

1. Folíolos pubérulos na face abaxial, flores $1,3-1,6 \mathrm{~cm}$ compr. A. fraxinifolia

1'. Folíolos tomentosos na face abaxial, flores $2-2,3 \mathrm{~cm}$ compr. A. ormosioides

1.1. Andira fraxinifolia Benth., Commentat. Legum. Gen. 44. 1837.

Material selecionado: BRASIL. SÃO PAULO: Ubatuba, Fazenda Capricónio, 30.I.2006, fr., E.D. Silva 835 (UEC).

Distribuição geográfica: Endêmica do Brasil (todas as regiões).

Domínio fitogeográfico brasileiro: Caatinga, Cerrado e Mata Atlântica.

1.2. Andira ormosioides Benth., Commentat. Legum. Gen. 44. 1837.

Material selecionado: BRASIL. SÃO PAULO: Ubatuba, Fazenda Capricónio, 7.IX.2007, E.D. Silva 912 (UEC).

Distribuição geográfica: Endêmica do Brasil (Sudeste e Nordeste).

Domínio fitogeográfico brasileiro: Mata Atlântica.

2. Cajanus Adans., Fam. Pl. 2: 326, 529. 1763.

2.1. Cajanus cajan (L.) Millsp., Publ. Field Columbian Mus., Bot. Ser. 2(1): 53. 1900.
Material selecionado: BRASIL. SÃO PAULO: Núcleo Santa Virgínia, Parque Estadual da Serra do Mar, 22.V.2008, fl., E.D. Silva 1118 (UEC, MBM).

Distribuição geográfica: Pantropical. Brasil (todas as regiões).

Domínio fitogeográfico brasileiro: Amazônia, Caatinga, Cerrado e Mata Atlântica.

3. Cochliasanthus Trew, Pl. Rar. 41, t. 10. 1763. Referência: Moreira 1997, Delgado-Salinas et al. 2011.

3.1. Cochliasanthus caracalla (L.) Trew, Pl. Rar. 41, t. 10. 1763.

Material selecionado: BRASIL. SÃO PAULO: Núcleo Santa Virgínia, Parque Estadual da Serra do Mar, 23.III.2009, fr., E.D. Silva 1210 (UEC, MBM, RB).

Distribuição geográfica: Pantropical. Brasil (Todas as regiões).

Domínio fitogeográfico brasileiro: Amazônia, Caatinga, Cerrado e Mata Atlântica.

4. Crotalaria L., Sp. Pl. 2: 714. 1753. Referências: Flores \& Miotto 2001, Flores 2004.

\section{Chave de identificação das espécies de Crotalaria no Parque Estadual da Serra do Mar, São Paulo}

1. Folhas simples.

2. Estípulas não decurrentes nos ramos C. juncea

2'. Estípulas decurrentes nos ramos C. breviflora

1'. Folhas trifolioladas.

3. Folíolos linear-elípticos a linear-lanceolados, estípulas ausentes, cálice $4 \mathrm{~mm}$ compr., lacínias muito menores que o tubo, legume estreito-oblongo C. lanceolata 
3'. Folíolos lanceolados ou elípticos, estípulas presentes, cálice 9-10 mm compr., lacínias maiores que o tubo, legume oblongo a largo-oblongo.

4. Pecíolo 5,5-7,5 cm compr., estípulas 3-11 mm, folíolos com até 2,1 cm larg., brácteas e bractéolas 7-9 mm compr., flores ca. $2 \mathrm{~cm}$ compr., legume $0,9-1,2 \mathrm{~cm}$ larg. C. micans

4'. Pecíolo 2-5,5 cm compr., estípulas 2-3 mm compr., folíolos 1,2-4,5 cm larg., brácteas e bractéolas 1-2 mm compr., flores ca. 1,2 cm compr., legume $0,5-0,8 \mathrm{~cm}$ larg.

C. vitellina

4.1. Crotalaria breviflora DC., Prodr. 2: 127. 1825.

Material selecionado: BRASIL. SÃO PAULO. Núcleo Santa Virgínia, Parque Estadual da Serra do Mar, 19.VII.2006, fl, E.D. Silva 375 (UEC).

Distribuição geográfica: Endêmica do Brasil (todas as regiões).

Domínio fitogeográfico brasileiro: Caatinga, Cerrado e Mata Atlântica.

4.2. Crotalaria juncea L., Sp. Pl. 2: 714. 1753. Material selecionado: BRASIL. SÃO PAULO: Núcleo Santa Virgínia, Parque Estadual da Serra do Mar, 24.V.2008, fl. e fr., E.D. Silva 1148 (UEC, MBM, RB).

Distribuição geográfica: Pantropical. Brasil (todas as regiões).

Domínio fitogeográfico brasileiro: Amazônia, Cerrado, Mata Atlântica, Pampa e Pantanal.

4.3. Crotalaria lanceolata E. Mey., Comm. Pl. Afr. Austr. 1: 24. 1836.

Material selecionado: BRASIL. SÃO PAULO. Núcleo Santa Virgínia, Parque Estadual da Serra do Mar, 28.I.2008, fl. e fr., E.D. Silva 1071 (UEC, MBM).

Distribuição geográfica: Pantropical. Brasil (todas as regiões).

Domínio fitogeográfico brasileiro: Amazônia, Cerrado, Mata Atlântica, Pampa e Pantanal.

4.4. Crotalaria micans Link, Enum. Hort. Berol. Alt. 2: 228. 1822.

Material selecionado: BRASIL. SÃO PAULO. Núcleo Santa Virgínia, Parque Estadual da Serra do Mar, 18.XII.2006, fl., E.D. Silva 610 (UEC, RB).

Distribuição geográfica: Pantropical. Brasil (todas as regiões).

Domínio fitogeográfico brasileiro: Amazônia, Caatinga, Cerrado, Mata Atlântica e Pampa.
4.5. Crotalaria vitellina Ker Gawl., Bot. Reg. 6: 447. 1820.

Material selecionado: BRASIL. SÃO PAULO: Núcleo Santa Virgínia, Parque Estadual da Serra do Mar, 17.XI.2007, fl., E.D. Silva 986 (UEC).

Distribuição geográfica: América Central e do Sul. Brasil (Sul, Sudeste, Centro-Oeste, Nordeste).

Domínio fitogeográfico brasileiro: Caatinga, Cerrado e Mata Atlântica.

5. Dahlstedtia Malme, Ark. Bot. 4(9): 4. 1905. Referências: Malme 1905, Burkart 1957, Teixeira \& Gabrielli 2000, Teixeira \& Ranga 2004, Silva et al. 2012.

5.1. Dahlstedtia pinnata Malme, Ark. Bot. 4(9): 4. 1905.

Espécie muito semelhante à Dahlstedtia pentaphylla (Taub.) Burkart, motivo pelo qual muitos autores às consideravam como uma única espécie. A presença de inflorescência ereta, lenticelas inconspícuas nos ramos florais e flores com corola púrpura são caracteres que podem auxiliar na identificação de $D$. pinnata. Apesar das duas espécies ocorrerem no estado de São Paulo, D. pinnata tem sua distribuição mais ao norte ocorrendo também no Rio de Janeiro enquanto $D$. pentaphylla está distribuída mais ao sul, nos estados do Paraná e Santa Catarina.

Material selecionado: BRASIL. SÃO PAULO: Ubatuba, Parque Estadual da Serra do Mar, Fazenda Capricórnio, 10.III.2007, fl., E.D. Silva 708 (UEC).

Distribuição geográfica: Endêmica do Brasil (Sudeste). Domínio fitogeográfico brasileiro: Mata Atlântica.

6. Dalbergia L. f., Suppl. Pl. 52. 1782. Referências: Hoehne 1941, Carvalho 1997.

\section{Chave de identificação das espécies de Dalbergia no Parque Estadual da Serra do Mar, São Paulo}

1. Árvores; ramos sem gavinhas ou ganchos; folhas ereto-patentes; folíolos com margens claramente revolutas D. brasiliensis

1'. Arbustos, lianas ou arvoretas escandentes; extremidades dos ramos com gavinhas ou ganchos; folhas pendentes; folíolos com margens planas ou levemente revolutas. 
2. Folhas 6-11 folioladas; folíolos 2,4-7 × 1,7-3,2 cm, ovado-lanceolados, face abaxial pubérula; peciólulo 2-4 mm compr. D. frutescens

2'. Folhas 15-23 folioladas; folíolos 1,3-1,9×0,5-0,9 cm, oblongos, face abaxial adpresso a patente-pilosa; peciólulo $1 \mathrm{~mm}$ compr.

D. lateriflora

6.1. Dalbergia brasiliensis Vogel, Linnaea 11: 198. 1837.

Material selecionado: BRASIL. SÃO PAULO: Parque Estadual da Serra do Mar - Núcleo Santa Virgínia, 27.I.2008, E.D. Silva 1054 (UEC).

Distribuição geográfica: Endêmica do Brasil (Sul e Sudeste).

Domínio fitogeográfico brasileiro: Cerrado e Mata Atlântica.

6.2. Dalbergia frutescens (Vell.) Britton, Bull. Torrey Bot. Club 16: 324. 1889.

Material selecionado: BRASIL. SÃO PAULO: Ubatuba-São Luiz do Paraitinga, Parque Estadual da Serra do Mar, 22.V.2008, fr., E.D. Silva 1110 (UEC, MBM, RB).
Distribuição geográfica: América do Sul. Brasil (Todas as regiões).

Domínio fitogeográfico brasileiro: Amazônia, Caatinga, Cerrado e Mata Atlântica.

6.3. Dalbergia lateriflora Benth., J. Linn. Soc. Bot. 4: 37. 1860.

Material selecionado: BRASIL. SÃO PAULO: Ubatuba, Parque Estadual da Serra do Mar, Fazenda Capricórnio, 11.VIII.2007, E.D. Silva 876 (UEC)

Distribuição geográfica: Emdêmica do Brasil (Sudeste e Nordeste).

Domínio fitogeográfico brasileiro: Mata Atlântica.

7. Desmodium Desv., J. Bot. Agric., 1: 122. 1813. Referência: Azevedo 1991.

\section{Chave de identificação das espécies de Desmodium no Parque Estadual da Serra do Mar, São Paulo}

1. Folíolos orbiculares a obovados com no máximo $3 \mathrm{~cm}$ compr. D. adscendens

1'. Folíolos elípticos a ovados com até $6,5 \mathrm{~cm}$ compr.

2. Artículos do lomento com uma margem reta e a outra levemente obtusa, ramos viscosos

D. uncinatum

2'. Artículos do lomento com um da margem reta e a outra arredondada, ramos não viscosos

3. Estípulas adnatas, pecíolo com até $2,6 \mathrm{~cm}$ compr. D. incanum

3'. Estípulas livres, pecíolo com até $6 \mathrm{~cm}$ compr. D. affine

7.1. Desmodium adscendens DC., Prodr., 2: 332. 1825.

Material selecionado: BRASIL. SÃO PAULO: Parque Estadual da Serra do Mar - Núcleo Santa Virgínia, 19.XII.2006, fl., E.D. Silva 615 (UEC).

Distribuição geográfica: Pantropical (Todas as regiões). Domínio fitogeográfico brasileiro: Amazônia, Caatinga, Cerrado, Mata Atlântica e Pampa.

7.2. Desmodium affine Schltdl.,Schltdl., Linnaea 12: 312. 1838.

Material selecionado: BRASIL. SÃO PAULO: Parque Estadual da Serra do Mar-Núcleo Santa Virgínia, 19.XII.2006, fl. e fr., E.D. Silva 616 (UEC).

Distribuição geográfica: América Central e do Sul. Brasil (Todas as regiões).

Domínio fitogeográfico brasileiro: Amazônia, Cerrado, Mata Atlântica, Pampa e Pantanal.
7.3. Desmodium incanum DC., Prodr., 2: 332. 1825.

Material selecionado: BRASIL. SÃO PAULO: Ubatuba, Parque Estadual da Serra do Mar, Fazenda Capricórnio, 14.X.2006, fl., E.D. Silva 462 (UEC)

Distribuição geográfica: Pantropical. Brasil (Todas as regiões).

Domínio fitogeográfico brasileiro: Amazônia, Caatinga, Cerrado, Mata Atlântica, Pampa e Pantanal.

7.4. Desmodium uncinatum (Jacq.) DC., (Jacq.) DC., Prodr. 2: 331. 1825.

Material selecionado: BRASIL. SÃO PAULO: Núcleo Santa Virgínia, Parque Estadual da Serra do Mar, 12.III. 2007, fl, E.D. Silva 719 (UEC, MBM, RB).

Distribuição geográfica: Pantropical. Brasil (Sul, Sudeste, Centro-Oeste e Nordeste).

Domínio fitogeográfico brasileiro: Caatinga, Cerrado, Mata Atlântica e Pampa. 
8. Dioclea Kunth, Nov. Gen. 5: 437. 1823.

\section{Chave de identificação das espécies de Dioclea no Parque Estadual da Serra do Mar, São Paulo}

1. Folíolos glabros em ambas as faces D. grandistipula

1'. Folíolos com a face abaxial canescente-velutina ou híspido-tomentosa D. rufescens

8.1. Dioclea grandistipula L.P. Queiroz, Novon 8(4): 433.1998.

Material selecionado: BRASIL. SÃO PAULO. Núcleo Santa Virgínia, Parque Estadual da Serra do Mar, 6.XI.2008, E.D. Silva 1166 (UEC).

Distribuição geográfica: Endêmica do Brasil (Sudeste). Domínio fitogeográfico brasileiro: Mata Atlântica.

8.2. Dioclea rufescens Benth., Comm. Legum. Gen. 69. 1837.

Material selecionado: BRASIL. SÃO PAULO. Núcleo Santa Virgínia, Parque Estadual da Serra do Mar, 19.XII.2006, f1., E.D. Silva 1117 (UEC, MBM).

Distribuição geográfica: Endêmica do Brasil (Sudeste).

Domínio fitogeográfico brasileiro: Mata Atlântica.
9. Lonchocarpus Kunth, Nov. Gen. Sp. 6: 300. 1824.Referências: Tozzi 1989, Neubert \& Miotto 1996, Silva et al. 2012.

9.1. Lonchocarpus cultratus (Vell.) A.M.G. Azevedo \& H.C. Lima, Acta Bot. Brasil. 9: 128, 141. 1995.

Material selecionado: BRASIL. SÃO PAULO: Ubatuba, Parque Estadual da Serra do Mar, Fazenda Capricórnio, 26.I.2008, fl., E.D. Silva 1033 (UEC).

Distribuição geográfica: América Central e do Sul. Brasil (Todas as regiões).

Domínio fitogeográfico brasileiro: Amazônia, Caatinga, Cerrado e Mata Atlântica.

10. Machaerium Pers., Syn. Pl. 2 (2): 276. 1807. Referências: Hoehne 1941b, Sartori \& Tozzi 1998, Mendonça-Filho 2002.

\section{Chave de identificação das espécies de Machaerium no Parque Estadual da Serra do Mar, São Paulo}

1. Folhas $15-35$ folioladas.

2. Lianas; acúleos uncinados.

3. Ramos jovens glabros; acúleos 1,5-2 mm compr.; folhas 17-21 folioladas; folíolos 0,5-1,3 cm larg., oblongos a obovados; flores creme M. uncinatum

3'. Ramos jovens fortemente tomentosos, acúleos $4 \mathrm{~mm}$ comp.; folhas 27-35 folioladas; folíolos 0,4-0,5 cm larg., linear-oblongos; flores lilases M. aculeatum

2'. Árvores; acúleos eretos a levemente encurvados.

4. Ramos jovens levemente tomentosos; acúleos 7-9 mm compr.; folhas 15-21 folioladas; folíolos elípticos M. scleroxylon

4'. Ramos jovens fortemente tomentosos; acúleos 5-17 mm compr.; folhas 19-29 folioladas; folíolos oblongos a levemente elípticos M. nictitans

1'. Folhas 5-9 folioladas.

5. Nervação craspedódroma, folíolos com a face abaxial serícea M. declinatum

5'. Nervação broquidódroma, folíolos glabros em ambas as faces ou face abaxial pubérula.

6. Folíolos lanceolados, folíolos glabros em ambas as faces, ramos sem gavinhas M. lanceolatum

6'. Folíolos elípticos, face abaxial pubérula, gavinhas aculeadas ocasionalmente presentes nos ramos M. debili

10.1. Machaerium aculeatum Raddi, Mem. Mat. Fis. Soc. Ital. Sci. Modena 18: 398. 1820. Material selecionado: BRASIL. SÃO PAULO: Ubatuba, Parque Estadual da Serra do Mar, Fazenda Capricórnio, 8.IX.2007, E.D. Silva 921 (UEC).
Distribuição geográfica: Endêmica do Brasil (Sudeste, Centro-Oeste e Nordeste).

Domínio fitogeográfico brasileiro: Cerrado, Mata Atlântica e Pantanal. 
10.2. Machaerium declinatum (Vell.) Stellfeld, Tribuna Farm. 12: 131. 1944.

Material selecionado: BRASIL. SÃO PAULO: Ubatuba, Parque Estadual da Serra do Mar, Fazenda Capricórnio, 11.VIII.2007, E.D. Silva 910 (UEC).

Distribuição geográfica: Endêmica do Brasil (Sudeste). Domínio fitogeográfico brasileiro: Mata Atlântica.

10.3. Machaerium debile (Vell.) Stellfeld, Tribuna Farm. 12: 131. 1944.

Material selecionado: BRASIL. SÃO PAULO: Núcleo Santa Virgínia, Parque Estadual da Serra do Mar, 24.V.2008, fr., E.D. Silva 1145 (UEC).

Distribuição geográfica: Endêmica do Brasil (Sudeste). Domínio fitogeográfico brasileiro: Mata Atlântica.

10.4. Machaerium lanceolatum (Vell.) J.F. Macbr., Field Mus. Nat. Hist., Bot. Ser. 13, 3: 281. 1943. Material selecionado: BRASIL. SÃO PAULO: Ubatuba, Parque Estadual da Serra do Mar, Fazenda Capricórnio, 8.IX.2007, E.D. Silva 918 (UEC).

Distribuição geográfica: Endêmica do Brasil (Sudeste, Centro-Oeste e Nordeste).

Domínio fitogeográfico brasileiro: Cerrado e Mata Atlântica.

10.5. Machaerium nictitans (Vell.) Benth., Commentat. Legum. Gen. 34. 1837.

Material selecionado: BRASIL. SÃO PAULO: Núcleo Santa Virgínia, Parque Estadual da Serra do Mar, 25.V.2008, fr., E.D. Silva 1156 (UEC, MBM, RB).

Distribuição geográfica: América do Sul. Brasil (Sul, Sudeste e Nordeste).

Domínio fitogeográfico brasileiro: Cerrado e Mata Atlântica.

10.6. Machaerium scleroxylon Tul., Arch. Mus. Hist. Nat. 4: 93. 1844.

Material selecionado: BRASIL. SÃO PAULO: Núcleo Santa Virgínia, Parque Estadual da Serra do Mar, 24.II.2008, E.D. Silva 1102 (UEC).
Distribuição geográfica: América do Sul. Brasil (Sul, Sudeste, Centro-Oeste e Nordeste).

Domínio fitogeográfico brasileiro: Cerrado e Mata Atlântica.

10.7. Machaerium uncinatum Benth., Commentat. Legum. Gen. 34. 1837.

Material selecionado: BRASIL. SÃO PAULO: Núcleo Santa Virgínia, Parque Estadual da Serra do Mar, 21.V.2007, E.D. Silva 831 (UEC).

Distribuição geográfica: Endêmica do Brasil (Sul, Sudeste e Nordeste).

Domínio fitogeográfico brasileiro: Mata Atlântica.

11. Mucuna Adans., Fam. Pl. 2: 325. 1763.

11.1. Mucuna urens (L.) Medik., Vorles. Churpfälz. Phys.-Öcon. Ges. 2: 399. 1787.

Material selecionado: BRASIL. SÃO PAULO: Ubatuba, Parque Estadual da Serra do Mar, Fazenda Capricórnio, 17.XII.2006, fl., E.D. Silva 605 (UEC).

Distribuição geográfica: América Central e do Sul. Brasil (Todas as regiões).

Domínio fitogeográfico brasileiro: Amazônia e Mata Atlântica.

11. Myrocarpus Allem., Diss. 1847. Referência: Sartori \& Tozzi 2004.

12.1. Myrocarpus frondosus Allem., Diss. 1848. Material selecionado: BRASIL. SÃO PAULO: Núcleo Santa Virgínia, Parque Estadual da Serra do Mar, 13.VIII.2007, E.D. Silva 901 (UEC).

Distribuição geográfica: América do Sul. Brasil (Sul, Sudeste e Nordeste).

Domínio fitogeográfico brasileiro: Mata Atlântica.

13. Ormosia Jacks., Trans. Linn. Soc. London, 10(2): 360. 1811. Referência: Rudd 1965.

\section{Chave para as espécies de Ormosia no Parque Estadual da Serra do Mar, São Paulo}

1. Folíolos oblongo-lanceolados, venação da face abaxial fortemente proeminente, flor vinácea a púrpura O. arborea

1'. Folíolos elípticos a obovados, venação da face abaxial não proeminente, flor lilás O. minor

13.1. Ormosia arborea (Vell.) Harms, Repert. Spec. Nov. Regni Veg. 19: 288. 1924.

Material selecionado: BRASIL. SÃO PAULO: Ubatuba, Parque Estadual da Serra do Mar, Fazenda Capricórnio, 23.V.2008, E.D. Silva 1127 (UEC).

Distribuição geográfica: Endêmica do Brasil (Sul, Sudeste e Nordeste).
Domínio fitogeográfico brasileiro: Cerrado e Mata Atlântica.

13.2. Ormosia minor Vogel, Linnaea 11:405.1837. Material selecionado: BRASIL. SÃO PAULO: Núcleo Santa Virgínia, Parque Estadual da Serra do Mar, 19.XII.2006, fr., E.D. Silva 617 (UEC). 
Distribuição geográfica: Endêmica do Brasil (Sudeste).

Domínio fitogeográfico brasileiro: Mata Atlântica.

14. Pterocarpus Jacq., Select. Stirp. Amer. Hist. 283. 1763.

14.1. Pterocarpus rohrii Vahl, Symb. Bot. 2: 79. 1791 .
Material selecionado: BRASIL. SÃO PAULO: Ubatuba, Parque Estadual da Serra do Mar, Fazenda Capricórnio, 17.I.2006, fr., E.D. Silva 486 (UEC).

Distribuição geográfica: América Central e do Sul. Brasil (Todas as regiões).

Domínio fitogeográfico brasileiro: Amazônia, Cerrado e Mata Atlântica.

15. Stylosanthes Sw., Prodr. 7: 108. 1788. Referências: Ferreira \& Costa 1979, Costa 1982, Fortuna-Perezetal.2011.

\section{Chave para identificação das espécies de Stylosanthes no Parque Estadual da Serra do Mar, São Paulo}

1. Subarbusto bastante ramificado, ramos fortemente híspido-glandulares, folhas pouco distanciadas $(2-3 \mathrm{~cm}$, aproximadamente) S. viscosa

1'. Subarbusto pouco ramificado, ramos tomentosos ou levemente híspido-glandulares, glabrescentes, folhas muito distanciadas (4-6 cm, aproximadamente) S. guianensis

15.1. Stylosanthes guianensis (Aubl.) Sw., Kongl. Vetensk. Acad. Nya Handl., 10: 301. 1789. Material selecionado: BRASIL. SÃO PAULO: Núcleo Santa Virgínia, Parque Estadual da Serra do Mar, 24.V.2008, fl., E.D. Silva 1154 (UEC).

Distribuição geográfica: Pantropical. Brasil (Todas as regiões).

Domínio fitogeográfico brasileiro: Cerrado e MataAtlântica.

15.2. Stylosanthes viscosa (L.) Sw., Prodr. 108. 1788.
Material selecionado: BRASIL. SÃO PAULO: Núcleo Santa Virgínia, Parque Estadual da Serra do Mar, 8.IX.2008, f1., E.D. Silva 1182 (UEC).

Distribuição geográfica: Pantropical. Brasil (Todas as regiões).

Domínio fitogeográfico brasileiro: Amazônia, Caatinga, Cerrado e Mata Atlântica.

16. Swartzia Schreb., Gen. P1. 2: 518. 1791. Referência: Cowan 1968, Mansano \& Tozzi 1999.

\section{Chave de identificação das espécies de Swartzia no Parque Estadual da Serra do Mar, São Paulo}

1. Folhas 5-7 folioladas, raque marginada a alada, folíolos glabros em ambas as face ..... S. langsdorffii

1'. Folhas 17-27 folioladas, raque cilíndrica a levemente marginada, folíolos pilosos em pelo menos uma das faces

2. Folhas $17-19$ folioladas, ramos glabros S. oblata

2'. Folhas 23-27 folioladas, ramos ferrugíneo-tomentosos

S. flaemingii

16.1. Swartzia flaemingii Raddi, Mem. Moden. 18(2): 397. 1820.

Material selecionado: BRASIL. SÃO PAULO: Núcleo Santa Virgínia, Parque Estadual da Serra do Mar, 7.IX.2008, fl., E.D. Silva 1174 (UEC, MBM, RB)

Distribuição geográfica: Endêmica do Brasil (Sudeste, Norte e Nordeste).

Domínio fitogeográfico brasileiro: Amazônia, Cerrado e Mata Atlântica.

16.2. Swartzia langsdorffii Raddi, Mem. Mod. 18(2): 396. 1820.

Material selecionado: BRASIL. SÃO PAULO: Núcleo Santa Virgínia, Parque Estadual da Serra do Mar, 26.I.2008, fl., E.D. Silva 1082 (UEC, MBM).
Distribuição geográfica: Endêmica do Brasil (Sudeste, Centro-Oeste e Nordeste).

Domínio fitogeográfico brasileiro: Mata Atlântica.

16.3. Swartzia oblata R.S. Cowan, Brittonia 33(1): 11. 1981.

Material selecionado: BRASIL. SÃO PAULO: Ubatuba, Parque Estadual da Serra do Mar, Fazenda Capricórnio, 23.II.2008, fl., E.D. Silva 1094 (UEC).

Distribuição geográfica: Endêmica do Brasil (Sul, Sudeste e Nordeste).

Domínio fitogeográfico brasileiro: Mata Atlântica.

17. Zollernia Maximil. \& Nees, Nova Acta Phys.Med. Acad. Caes. Leop.-Carol. Nat. Cur. 13(2): 13. 1827. Referência: Mansano et al. 2004. 
17.1. Zollernia ilicifolia (Brongn.) Vogel, Linnaea 11: 166. 1837.

Material selecionado: BRASIL. SÃO PAULO: Ubatuba, Parque Estadual da Serra do Mar, Fazenda Capricórnio, 26.I.2008, E.D. Silva 1047 (UEC).

Distribuição geográfica: América do Sul. Brasil (Todas as regiões).

Domínio fitogeográfico brasileiro: Caatinga, Cerrado e Mata Atlântica.

18. Zornia J. F. Gmel., Sist. nat., 2 (2): 1076. 1792. Referências: Mohlenbrock 1961, Sciamarelli \& Azevedo-Tozzi 1996, Perez 2009.

18.1. Zornia curvata Mohlenbr., Webbia, 16: 132. 1961.

Material selecionado: BRASIL. SÃO PAULO: Núcleo Santa Virgínia, Parque Estadual da Serra do Mar, 28.I.2008, fr., E.D. Silva 1081 (UEC).

Distribuição geográfica: América Central e do Sul. Brasil (Todas as regiões).

Domínio fitogeográfico brasileiro: Amazônia, Caatinga, Cerrado, Mata Atlântica, Pampa e Pantanal.

A família Leguminosae está bem representada na Floresta Ombrófila Densa do Núcleo Santa Virgínia quando comparamos os dados obtidos na área de estudo com os resultados apresentados em levantamentos realizados em outras áreas da Floresta Atlântica nos estados de São Paulo, Rio de Janeiro e Paraná (Tab. 1), ressalvadas as diferenças que dificultam as comparações entre as áreas, como: metodologia empregada no estudo, tamanho da área amostral, níveis de preservação de cada área, dificuldade de acesso aos locais de coleta, delimitação dos parâmetros de inclusão do indivíduo na amostragem, entre outros. A diversidade de tribos e gêneros de Leguminosae encontrada na área de estudo sugere que esses táxons desempenham papel importante na composição dessa floresta. Gêneros neotropicais como Machaerium e Inga, bem representados em número de espécies em Santa Virgínia, revelam a importante contribuição da família na formação das florestas brasileiras, em especial da Floresta Atlântica. O número elevado de espécies ocorrentes na área de estudo indica que a presença da família nas formações florestais do litoral norte de São Paulo é ainda mais significativa do que o anteriormente estimado. A diferença observada no número de espécies amostradas em levantamento florísticos comparado aos fitossociológicos talvez realce a necessidade dos levantamentos fitossociológicos de formações naturais serem precedidos e complementados por levantamentos florísticos, como já observado por Rodrigues \& Shepherd (1992) em levantamento realizado na Serra do Japi. O número de espécies endêmicas da Floresta Atlântica encontrado na área de estudo (27) mostra que, apesar da capacidade da família em ocupar diversos habitats, muitas leguminosas desenvolvem-se apenas em áreas restritas de fitofisionomias específicas. Em função do atual declínio das formações florestais brasileiras, principalmente em decorrência da expansão urbana e agrícola, a afirmação de que determinadas áreas são importantes centros de endemismo de várias famílias de plantas pode sustentar decisões que visem a definição de estratégias de conservação para uma região, visto que espécies com distribuição restrita requerem atenção especial para preservação. Conhecer as espécies ocorrentes em remanescentes de florestas, principalmente aquelas de distribuição restrita, é de fundamental importância para o desenvolvimento de estratégias de conservação que dependem, em especial, do conhecimento da diversidade biológica de uma área. Este conhecimento tem sido valorizado nos programas estabelecidos pelas políticas públicas, evidenciando a necessidade de qualificar, quantificar e modelar sua biodiversidade. Neste sentido, é relevante a associação da composição florística com dados de distribuição geográfica das espécies, e esses dados contribuirão, indubitavelmente, para um maior conhecimento dos padrões de distribuição e ecologia das famílias, como também servirão de apoio a futuras medidas preservacionistas.

\section{Agradecimentos}

Nossos sinceros agradecimentos à Fundação de Amparo à Pesquisa do Estado de São Paulo - FAPESP (Projeto Biota Gradiente Funcional - 03/12595-7); ao Fundo de Apoio ao Ensino, à Pesquisa e à Extensão - FAEPEX/UNICAMP o apoio financeiro; à direção e aos funcionários do Instituto Florestal - Núcleo Santa Virgínia a hospedagem e apoio durante todo trabalho; aos administradores e funcionários da Fazenda Capricórnio a permissão e auxílio durante as coletas.

\section{Referências}

Altschul, S. von R. 1964. A taxonomic study of the genus Anadenanthera. Contributions from the Gray Herbarium of Harvard University 193: 1-65. 
Azevedo, A.M.G. 1981. O gênero Desmodium Desv. no Brasil: considerações taxonômicas. Tese de Mestrado. Universidade Estadual de Campinas, Campinas. 315p.

Barneby, R.C. 1991. Sensitivae Censitae. A Descrition of the Genus Mimosa Linnaeus (Mimosaceae) in the New World. Memoirs of the New York Botanical Garden. Vol. 65. 835p.

Barneby, R.C. \& Grimes, J.W. 1996. Silk Tree, Guanacaste, Monkey's Earring: A generic system for the synandrous Mimosaceae of the Americas. Part I. Abarema, Albizia, and Allies. Memoirs of the New York Botanical Garden 74: 1-192.

Barneby, R.C. \& Heald, S.V. 2002a. Caesalpiniaceae. In: Mori, S.A.; Cremers, G.; Gracie, C.A.; Granville, J.J.; Heald, S.V.; Hoff. M.; Mitchell, J.D. (eds.). Guide to the Vascular Plants of Central French Guiana. Memoirs of the New York Botanical Garden 76: 167-183.

Barneby, R.C. \& Heald, S.V. 2002b. Fabaceae (Bean Family). In: Mori, S.A.; Cremers, G.; Gracie, C.A.; Granville, J.J.; Heald, S.V.; Hoff. M.; Mitchell, J.D. (eds.). Guide to the Vascular Plants of Central French Guiana. Memoirs of the New York Botanical Garden 76: 298-319.

Barros, F.; Melo, M.M.R.F.; Chiea, S.A.C.; Kirizawa, M.; Wanderly, M.G. \& Jung- Mendaçolli, S.L. 1991. Flora Fanerogâmica da Ilha do Cardoso: Caracterização geral e lista das espécies ocorrentes. Vol.1. Instituto de Botância, São Paulo. 184p.

Barros, M.J.F. 2011. Senegalia Raf. (Leguminosae, Mimosoideae) do Domínio Atlântico, Brasil. Dissertação de Mestrado. Instituto de Pesquisas Jardim Botânico do Rio de Janeiro, Escola Nacional de Botânica Tropical, Rio de Janeiro. 138p.

Barroso, G.M. 1965. Leguminosas da Guanabara. Arquivos do Jardim Botânico do Rio de Janeiro 18: 109-177.

Barroso, G.M.; Peixoto, A.L.; Ichaso, C.L.F.; Costa, C.G.; Guimarães, E.F. \& Lima, H.C. 1986. Sistemática de angiospermas do Brasil. Vol. 3. Ed. Imprensa Universitária, Viçosa. 326p.

Barroso, G.M.; Morim, M.P.; Peixoto, A.L. \& Ichaso C.L.F. 1999. Frutos e sementes: morfologia aplicada à sistemática de dicotiledôneas. Ed. UFV, Viçosa. Pp. 168-224.

Bentham, G., 1862. Leguminosae. In: Martius, C.F.P. \& Eichler, A.G. (eds.). Flora brasiliensis. Monachii, Fri. Fleischer. Vol. 15. Partes 1 e 2. 527p.

Burkart, A. 1957. Dahlstedtia pentaphylla (Taub.) Burkart, nov. comb. Darwiniana 11: 269.

Camargo, R.A. \& Miotto, S.T.S. 2004. O gênero Chamaecrista Moench (LeguminosaeCaesalpinioideae) no Rio Grande do Sul. Iheringia 59: 131-148.

Carvalho, A. M. 1997. A synopsis of the genus Dalbergia (Fabaceae: Dalbergieae) in Brazil. Brittonia 49: 87-109.
Costa, N.M.S. \& Ferreira, M.B. 1982. O gênero Stylosanthes em Minas Gerais. EPAMIG, Belo Horizonte. 56p.

Cowan, R. S. 1968. Swartzia (LeguminosaeCaesalpinioideae, Swartzieae). Flora Neotropica Monograph 1. Hafner, New York. 228p.

Cowan, R.S. 1981. Caesalpinioideae. In: Polhill, R.M \& Raven, P.H. (eds.). Advances in legume systematics. Vol. 1. Royal Botanic Garden, Kew. Pp.57-64.

Delgado-Salinas, A.; Thulin, M.; Pasquet, R.; Weeden, N. \& Lavin, M. 2011. Vigna (Leguminosae) sensu lato: The names and identities of the American segregate genera. American Journal of Botany 98: 1694-1715.

Dwyer, J.D. 1957. The Tropical American Sclerolobium Vogel (Caesalpiniaceae). LLoydia 20: 67-119.

Elias, T.S. 1981. Mimosoideae. In: Polhill, R.M \& Raven, P.H. (eds.). Advances in legume systematics. Vol.1. Royal Botanic Garden, Kew. Pp.143-152.

Ferreira, M.B. \& Costa, N.M.S. 1979. O gênero Stylosanthes Sw. no Brasil. EPAMIG, Belo Horizonte. 108p.

Forza, R.C. et al. (eds.). 2012. Lista de espécies da flora do Brasil. Disponível em $<$ http://floradobrasil.jbrj. gov.br/2012>. Acesso em 6 Mai 2012.

Flores, A.S. \& Miotto S.T.S. 2001. O gênero Crotalaria L. (Leguminosae-Faboideae) na Região Sul do Brasil. Iheringia 55: 189-247.

Flores, A.S. 2004. Taxonomia, números taxonômicos e química de espécies de Crotalaria L. (LeguminosaePapilionoideae) no Brasil. Tese de Doutorado. Universidade Estadual de Campinas, Campinas. 201p.

Fortuna-Perez, A.P.; Silva, M.J. \& Tozzi, A.M.G.A. 2011. Stylosanthes (Leguminosae Papilionoideae Dalbergiae) no estado de São Paulo, Brasil. Rodriguesia 62: 615-628.

Fortunato, R.H. 1986. Revision del genero Bauhinia (Cercideae, Caesalpinioidea, Fabaceae) para la Argentina. Darwiniana 27: 527-557.

Garcia, F.C.P. 1998. Relações sistemáticas e fitogeografia do gênero Inga Miller (Leguminosae, Mimosoideae, Ingeae) nas florestas da costa sul e sudeste do Brasil. Tese de Doutorado. Universidade Estadual Paulista. Rio Claro. 248p.

Grimes, J.W. 2002. Mimosaceae. In: Mori, S.A.; Cremers, G.; Gracie, C.A.; Granville, J.J.; Heald, S.V.; Hoff. M.; Mitchell, J.D. (eds.). Guide to the vascular plants of Central French Guiana. Memoirs of the New York Botanical Garden 76: 484-510.

Hoehne, F.C. 1941a. Leguminosas-Papilionadas: gêneros Dalbergia e Cyclolobium. Flora Brasilica 25: 1-39.

Hoehne, F.C. 1941b. Leguminosas-Papilionadas: Gêneros Machaerium e Paramachaerium. Flora Brasilica 25: 1-99.

Iganci, J.R.V. \& Morim, M.P. 2012. Abarema (Fabaceae, Mimosoideae) in the Atlantic Domain, Brazil. Botanical Journal of the Linnean Society 168: 473. 
Irwin, H.S. \& Barneby, R.C. 1982a. The American Cassinae: a synoptical revision of Leguminosae. Tribe Cassieae subtribe Cassiinae in the New World. Memoirs of the New York Botanical Garden 35: 1-454.

Irwin, H.S. \& Barneby, R.C. 1982b. The American Cassinae: ASynoptical Revision of Leguminosae. Tribe Cassieae subtribe Cassiinae in the New World. Memoirs of the New York Botanical Garden 35: 455-918.

Ilds. 2012. International Legume Database \& Information Service. Disponível em <http://www.ilds.org>. Acesso em 23 Mai 2012.

Kronka, F.J.N.; Nalon, M.A.; Matsukuma, C.K.; Pavão, M.; Ywane, M.S.S.; Kanashiro, M. M.; Lima, L.M.P.R.; Pires, A.S.; Shida, C.N; Fukuda; J.C.; Guillaumon J.R.; Barbosa, O.; Barradas, A.M.F.; Borgo, S.C.; Monteiro, C.H.B.; Pontinhas, A.A.S.; Andrade G.G.; Joly, C.A.; Couto, H.T.Z. \& Baitello, J.B. 2003. O verde em São Paulo. Pesquisa FAPESP 91: 48-53.

Lacerda, M.S. 2001. Composição florística e estrutura da comunidade arbórea num gradiente altitudinal da Mata Atlântica. Tese de Doutorado. Universidade Estadual de Campinas. 122p.

Leitão-Filho, H. F. 1994. Diversity of arboreal species in atlantic rain forest. Anais da Academia Brasileira de Ciências 66: 91-96.

Lewis, G.P. 1987. Legumes of Bahia. Royal Botanical Gardens, Kew. 369p.

Lewis, G.P. \& Lima, L.P.M. de 1991. Pseudopiptadenia no Brasil. (Leguminosae: Mimosoideae). Arquivos do Jardim Botânico do Rio de Janeiro 30: 43-67.

Lewis, G.P.; Schrire, B.; Mackinde, B. \& Lock, M. 2005. Legumes of the world. Royal Botanic Gardens, Kew. $577 \mathrm{p}$.

Lima, H.C. 2000. Leguminosas arbóreas da Mata Atlântica. Tese de Doutorado. Universidade Federal do Rio de Janeiro, Rio de Janeiro. 157p.

Lima, H.C.; Fortuna-Perez, A.P.; Tozzi, A.M.G.A.; Flores, A.S.; Vaz, A.M.S.F.; Klitgaard, B.B.; Cardoso, D.B.O.S.; Filardi, F.L.; Garcia, F.C.P.; Lewis, G.P.; Iganci, J.R.V.; Meireles, J.E.; Valls, J.F.M.; Lima, L.C.P.; Queiroz, L.P.; Silva, M.J.; Morim, M.P.; Barros, M.J.F.; Queiroz, R.T.; Fortunato, R.H.; Pennington, R.T.; Miotto, S.T.S.; Moura, T.N.; Dutra, V.F.; Mansano, V.; Souza, V.C.; Scalon, V.C. 2009. Fabaceae (Leguminosae). In: Stehmann, J.R.; Forzza, R.C.; Salino, A; Sobral, M.; Costa, D.P. \& Kamino, L.H.Y. (orgs.). Plantas da Floresta Atlântica. Jardim Botânico do Rio de Janeiro, Rio de Janeiro. Pp. 259-283.

Lima, H.C.; Queiroz, L.P.; Morim, M.P.; Souza, V.C.; Dutra, V.F.; Bortoluzzi, R.L.C.; Iganci, J.R.V.; Fortunato, R.H.; Vaz, A.M.S.F.; Souza, E.R.;Filardi, F.L.R.; Valls, J.F.M.; Garcia, F.C.P.; Fernandes, J.M.; Martins-da-Silva, R.C.V.; Perez, A.P.F.; Mansano, V.F.; Miotto, S.T.S.; Tozzi, A.M.G.A.; Meireles, J.E.; Lima, L.C.P.; Oliveira, M.L.A.A.; Flores, A.S.;
Torke, B.M.; Pinto, R.B.; Lewis, G.P.; Barros, M.J.F.; Schütz, R.; Pennington, T., Klitgaard; B.B.; Rando, J.G.; Scalon, V.R.; Cardoso, D.B.O.S.; Costa, L.C.; Silva, M.J.; Moura, T.M.; Barros, L.A.V.; Silva, M.C.R.; Queiroz, R.T.; Sartori, A.L.B. \& Camargo, R. 2012. Fabaceae In: Forzza, R.C. et al. (eds.). Lista de espécies da flora do Brasil. Jardim Botânico do Rio de Janeiro. Disponível em <http://floradobrasil. jbrj.gov.br/2012/FB000115>. Acesso em 6 Jul 2012.

Malme, G. 1905. Dahlstedtia, eine neue Leguminosen - Gattung. Arkiv för Botanik 4:1-7.

Mansano, V.F. \& Tozzi, A.M.G.A. 1999. The taxonomy of some Swartzieae (Leguminosae, subfm. Papilonoideae) from southeastern Brazil. Brittonia 51: 149-158.

Mansano, V.F. \& Tozzi, A.M.G.A. \& Lewis, G.P. 2004. A revision of the South American genus Zollernia Wied-Neuw. \& Nees (Leguminosae, Papilionoideae, Swartzieae). Kew Bulletin 59: 497-520.

Mamede, M.C.H.; Cordeiro, I.; Rossi, L.; Melo, M.M.R.F. \& Oliveira, R.J. 2004. Mata Atlantica. In: Marques, A.O.V. \& Duleba, W. (eds.). Estação Ecológica Juréia-Itatins: ambiente físico, flora e fauna. Holos Editora, Ribeirão Preto. Pp.115-132.

Marques, M.C. M.; Vaz, A.S.F. \& Marquete, R. (orgs.). 1997. Flórula da APA Cairuçu. Parati. Espécies vasculares. Instituto de Pesquisas Jardim Botânico do Rio de Janeiro. Série estudos e contribuições 14: 9-576.

Mendonça-Filho, C.V. 2002. Citotaxonomia de Machaerium Pers. Sect. Oblonga (Benth.) Taub. (Leguminosae-Papilionoideae). Tese de Doutorado. Universidade Estadual de Campinas. 208p.

Moreira, J.L.A. 1997. Estudo taxonômico da subtribo Phaseolinae Benth. (Leguminosae-Papilionoideae) no Sudeste e Centro-Oeste do Brasil. Tese de Mestrado. Universidade Estadual de Campinas, Campinas. 292p.

Mohlenbrock, R.H. 1961. A monograph of the leguminous genus Zornia. Webbia 16: 1-141.

Mori, S.A.; Boom, B.M. \& Prance, G.T. 1981. Distribuition patterns and conservation of eastern Brazilian coastal forest tree species. Brittonia 33: 233-245.

Neubert, E.E. \& Miotto, S.T.S. 1996. O gênero Lonchocarpus Kunth (Leguminosae-Faboideae) no Rio Grande do Sul. Iheringia 47: 73-102.

Perez, A.P.F. 2009. O gênero Zornia J.F. Gmel. (Leguminosae, Papilionoideae, Dalbergieae): revisão taxonômica das espécies ocorrentes no Brasil e filogenia. Tese de Doutorado. Universidade Estadual de Campinas, Campinas. 271p.

Polhill, R.M \& Raven, P.H. (eds.). 1981. Advances in legume systematics. Vol. 1. Royal Botanic Garden, Kew. Pp.191-205.

Pennington, T.D. 1997. The genus Inga. The Royal Botanical Garden. Kew. 839p. 
Pennington, T.D. 2003. Monograph of Andira (Leguminosae-Papilionoideae). Systematic Botany Monographs 67: 1-113.

Queiroz, L.P. 2009. Leguminosas da caatinga. Universidade Estadual de Feira de Santana, Feira de Santana. 467p.

Rico-Arce, M.L. 2007. American species of Acacia. Royal Botanical Gardens, Kew. 207p.

Rodrigues, R.R. \& Shepherd, G.J. 1992. Análise da variação estrutural e fisionômica da vegetação e características edáficas, num gradiente altitudinal na Serra do Japi. In: Morellato, L.P.C. (coord.). História natural da Serra do Japi: ecologia e preservação de uma área florestal no sudeste do Brasil. Ed. Universidade de Campinas, Campinas. Pp. 64-97

Rodrigues, R.S.; Flores, A.S.; Miotto, S.T.S. \& Baptista, L.R.M. 2005. O gênero Senna (Leguminosae -Caesalpinioideae) no Rio Grande do Sul, Brasil. Acta Botanica Brasilica 19: 1-16.

Rudd, V.E. 1965. The American species of Ormosia (Leguminosae). Contributions from the United States National Herbarium 32: 278-384.

Sartori, A.L.B. \& Tozzi, A.M.G.A. 1998. As espécies de Machaerium Pers. (Leguminosae-PapilionoideaeDalbergieae) ocorrentes no estado de São Paulo. Revista Brasileira de Botânica 21: 211-246.

Sartori, A.L.B. \& Azevedo-Tozzi, A. M. G. 2004. Revisão taxonômica de Myrocarpus Allemão (Leguminosae Papilionoideae Sophoreae). Acta Botanica Brasilica 18: 521-535.

Sciamarelli, A. \& Azevedo-Tozzi, A.M.G. 1996. Zornia J.F.Gmel. (Leguminosae-PapilionoideaeAeschynomeae) no estado de São Paulo. Acta Botanica Brasilica 10: 237-266.

Seigler, D.S.; Ebinger, J.E. \& Miller, J.T. 2006. The genus Senegalia (Fabaceae: Mimosoideae) from the new world. Phytologia 88: 38-94.

Setzer, J. 1966. Atlas climatológico do estado de São Paulo. Comissão interestadual da bacia do ParanáParaguai. Cesp, São Paulo. 239p.

Schmidlin, L.A.J.; Accioly, A.; Accioly, P. \& Kirchner, F.F. 2005. Mapeamento e caracterização de Superagui utilizando técnicas de geoprocessamento. Floresta 35: 303-305.

Silva, A.F. \& Leitão-Filho, H.F. 1982. Composição florística e estrutura de um trecho da Mata Atlântica de encosta no município de Ubatuba, São Paulo, Brasil. Revista Brasileira de Botânica 5: 43-52.
Silva, M.J.; Queiroz, L.P.; Tozzi, A.M.G.A.; Lewis G.P. \& Sousa, A.P. 2012. Phylogeny and biogeography of Lonchocarpus sensu lato and its allies in the tribe Millettieae (Leguminosae, Papilionoideae). Taxon 61: 93-108.

Silva, S.M. 1998. As formações vegetais da planície litorânea da Ilha do Mel, Paraná, Brasil: composição florística e principais características estruturais. Tese de Doutorado. Universidade Estadual de Campinas. Campinas. 262p.

Species link. 2012. Centro de Referência em Informação Ambiental \& Fundação de Amparo à Pesquisa do Estado de São Paulo. Disponível em $<$ http://www. splink.cria.org.br>. Acesso em 8 Jun 2012.

Tamashiro, J.Y. 1989. Estudos taxonômicos e morfológicos do gênero Piptadenia sensu Bentham no Sudeste do Brasil. Avaliação das modificações taxonômicas recentemente propostas. Tese de Mestrado. Universidade Estadual de Campinas. 96p.

Teixeira, S.P. \& Gabrielli, A.C. 2000. Anatomia do eixo vegetativo de Dahlstedtia pinnata (Benth.) Malme e D. pentaphylla (Taub.) Burkart (Leguminosae, Papilionoideae). Revista Brasileira de Botânica 23: 1-11.

Teixeira, S.P. \& Ranga, N.T. 2004. Biosystematics of the genus Dahlstedtia Malme (Leguminosae, Papilionoideae, Millettieae). Revista Brasileira de Botânica 27: 37-45.

Thiers, B. [continuously updated]. Index Herbariorum: a global directory of public herbaria and associated staff. New York Botanical Garden's Virtual Herbarium. Disponível em < http://sweetgum.nybg. org/ih/>. Acesso em 15 Jun 2012

Tozzi, A.M.G.A. 1989. Estudos taxonômicos dos gêneros Lonchocarpus Kunth e Deguelia Aubl. no Brasil. Tese de Doutorado. Universidade Estadual de Campinas. 341p.

Ulibarri, E.A. 1996. Sinopsis de Caesalpinia y Hoffmannseggia (Leguminosae-Caesalpinioideae) de Sudamérica. Darwiniana 34: 299-344.

Vaz, A.M.S.F. 1979. Considerações sobre a taxonomia do gênero Bauhinia L. sect. Tylotaea (Leguminosae Caesalpinioideae) do Brasil. Rodriguésia 31: 127-234.

Vaz, A.M.S.F. 1993. Trepadeiras do gênero Bauhinia (Caesalpiniaceae). Pesquisa Botânica 44: 95-114.

Veloso, H.P.; Rangel-Filho, A.L.R. \& Lima, J.C.A. 1991. Classificação da vegetação brasileira adaptada a um sistema universal. IBGE, Rio de Janeiro. 112p.

Wittaker, R.H. 1975. Communities and ecosystems. Macmillan, New York. 385p. 